\title{
Implementation of a Nonverbal Scrub Cap Identification System to Improve Communication and Perception of Patient Safety Among Unfamiliar, De-identified Staff Members in the Operating Room.
}

Keri Ann Roskowinski

kroskowi@mix.wvu.edu

Follow this and additional works at: https://researchrepository.wvu.edu/etd

Part of the Communication Sciences and Disorders Commons, Nursing Commons, and the Quality Improvement Commons

\section{Recommended Citation}

Roskowinski, Keri Ann, "Implementation of a Nonverbal Scrub Cap Identification System to Improve Communication and Perception of Patient Safety Among Unfamiliar, De-identified Staff Members in the Operating Room." (2022). Graduate Theses, Dissertations, and Problem Reports. 10194.

https://researchrepository.wvu.edu/etd/10194

This Thesis is protected by copyright and/or related rights. It has been brought to you by the The Research Repository @ WVU with permission from the rights-holder(s). You are free to use this Thesis in any way that is permitted by the copyright and related rights legislation that applies to your use. For other uses you must obtain permission from the rights-holder(s) directly, unless additional rights are indicated by a Creative Commons license in the record and/ or on the work itself. This Thesis has been accepted for inclusion in WVU Graduate Theses, Dissertations, and Problem Reports collection by an authorized administrator of The Research Repository @ WVU. For more information, please contact researchrepository@mail.wvu.edu. 
Implementation of a Nonverbal Scrub Cap Identification System to Improve Communication and Perception of Patient Safety Among Unfamiliar, Deidentified Staff Members in the Operating Room

Keri A. Adams

Doctor of Nursing Practice Dissertation submitted to the School of Nursing at West Virginia University

In partial fulfillment of the requirements for the degree of Doctor of Nursing Practice in Nurse Anesthesia

\author{
Aaron Ostrowski, DNP, APRN, CRNA, Chair \\ Chad Crigger, MD \\ Department of Nurse Anesthesia
}

\title{
Morgantown, West Virginia \\ 2021
}

Keywords: Identification, scrub cap, nonverbal communication, unfamiliar staff, communication breakdown, personal protective equipment, patient safety 


\title{
ABSTRACT \\ Implementation of a Nonverbal Scrub Cap Identification System to Improve Communication and Perception of Patient Safety Among Unfamiliar, Deidentified Staff Members in the Operating Room
}

\author{
Keri Ann Adams
}

\begin{abstract}
Background: Operating room (OR), professionals deliver patient care with brief introductions, and roles were not always identified, and although team members wear identification (ID) badges, they were usually covered by sterile gowns and other routine personal protective equipment (PPE). Purpose: The aim of this Doctor of Nursing Practice (DNP) project was to determine if a simple intervention to apply the individual's name and role to a scrub cap could improve identification, OR team communication, and consequently, patient safety. The participants in this project consisted of nurses, physicians, anesthesia providers, scrub technicians, students, medical sales representatives, and those that identified as "other," yielding 51 pre-survey and 44 post intervention responses. Methods: of this quality improvement project, which spanned two months in the urological ORs in a teaching hospital in West Virginia, involved the implementation of a nonverbal communication strategy requesting participants to affix their name and role onto the outside of their scrub cap upon entering the case. The intervention aims to determine the effectiveness of this strategy in improving communication and the perception of patient's safety when fully donned in PPE among unfamiliar, deidentified team members. The participants provided feedback on the intervention through electronic and paper formatted pre- and post-surveys. Eleven paper copies were discarded due to multiple selections for 1 response only questions. Results: The mean, median, mode, and standard deviation were evaluated based on demographic data obtained from the surveys. In addition, A Mann-Whitney $U$ Test was conducted to determine the participant's perception on enhanced patient safety after the intervention which yielded results that were not statistically significant ( $\mathrm{p}=0.856$ ). Conclusion: while results were not statistically significant, further investigation is required to determine the effect of a nonverbal identification system on patient safety as staff perceived improved identification of OR team members and communication.

Search terms: deidentified, unfamiliar staff, communication breakdown, PPE, challenges, barriers, identification, patient harm.
\end{abstract}


Table of Contents

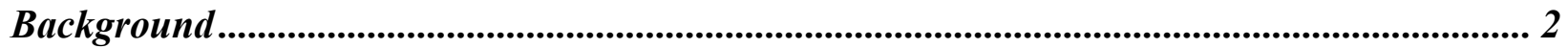

Problem Description .................................................................................................................. 2

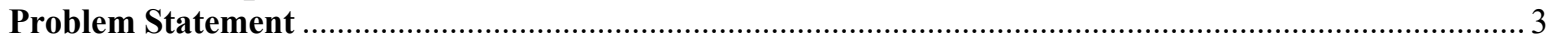

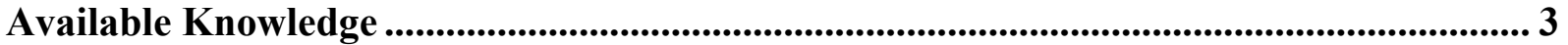

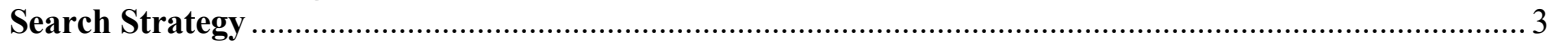

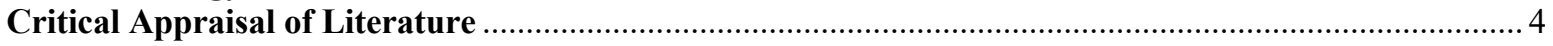

Literature Review Synthesis ............................................................................................................. 7

Rationale ...................................................................................................................................... 9

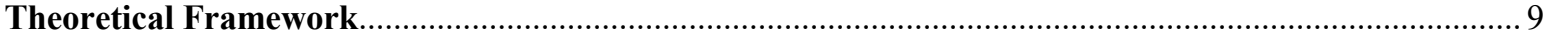

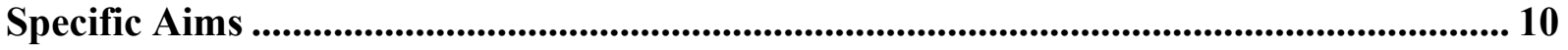

Purpose

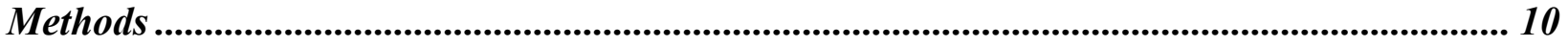

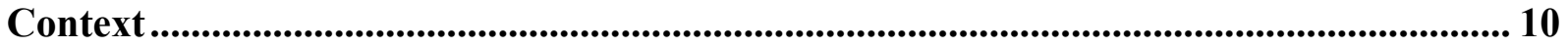

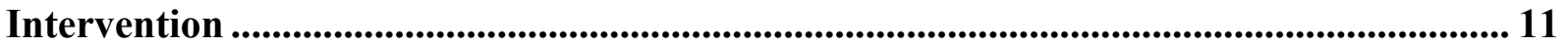

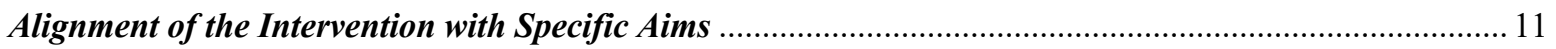

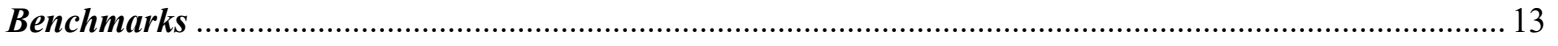

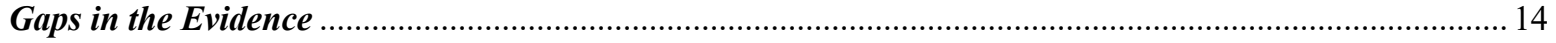

Congruence with the Organization's Strategic Plan ........................................................................... 14

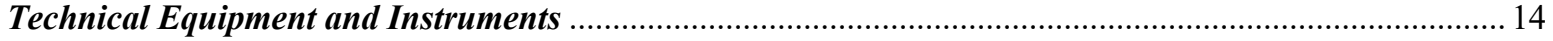

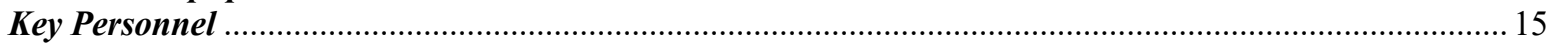

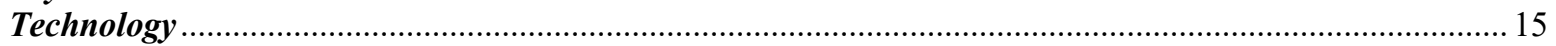

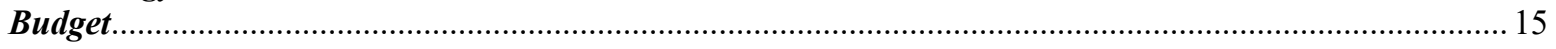

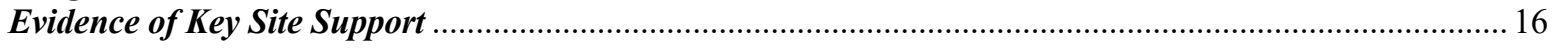

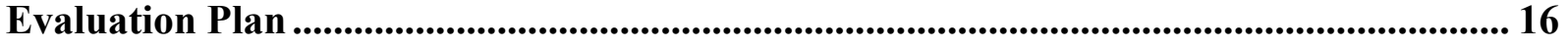

Assessing the Impact of the Intervention ................................................................................................ 16

Project Objectives: Correlation between Project Outcomes and the Intervention ...................................... 16

Strategies to Achieve the Specific Aims ............................................................................................ 17

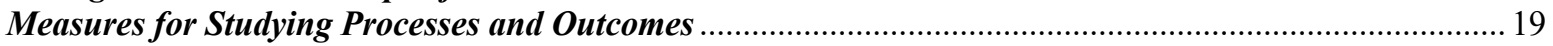

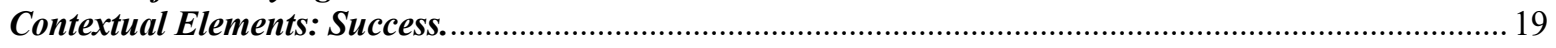

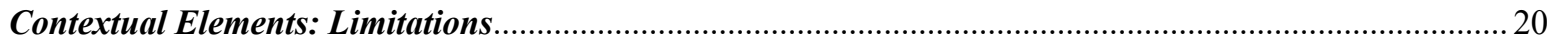

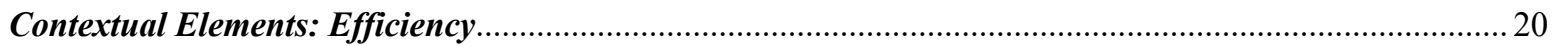

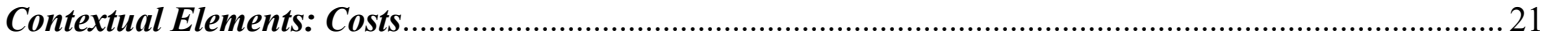

Methods to Assess Data Completeness and Accuracy ....................................................................... 21

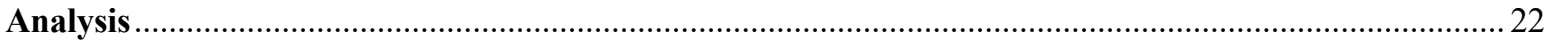

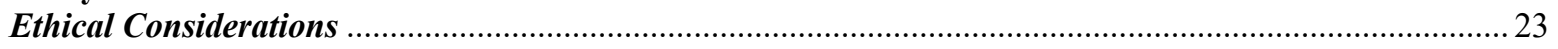

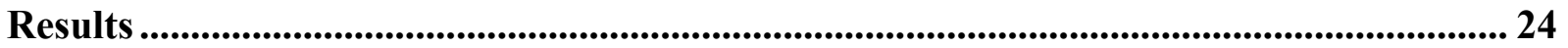

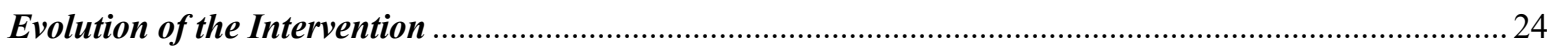

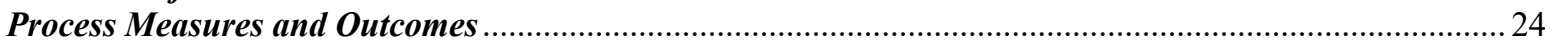

Contextual Elements Associated with the Intervention....................................................................... 40

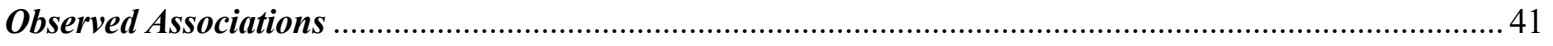

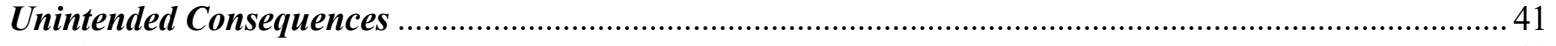

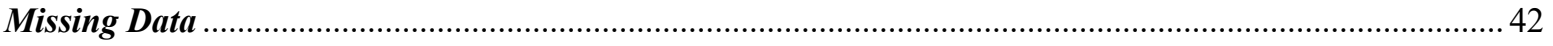

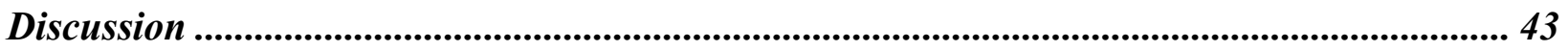




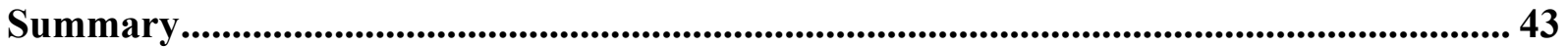

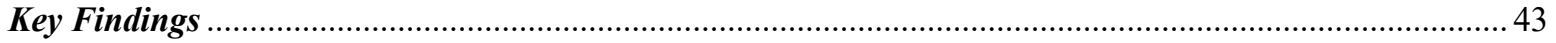

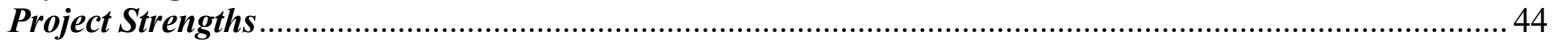

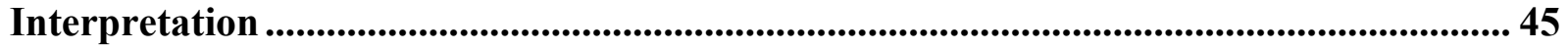

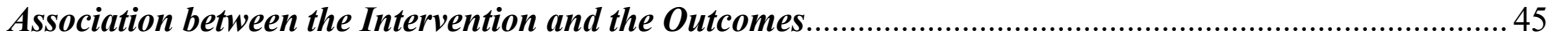

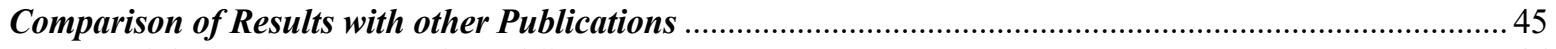

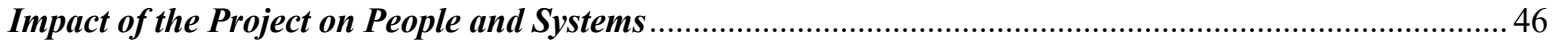

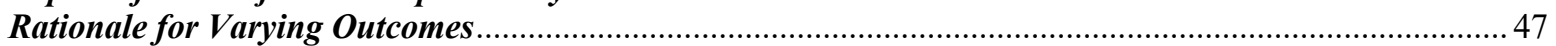

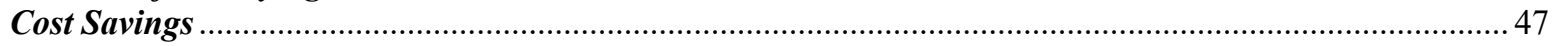

Limitations ................................................................................................................................. 48

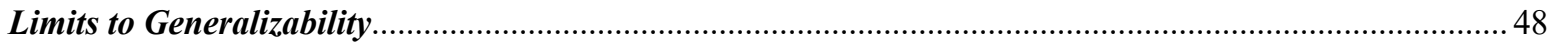

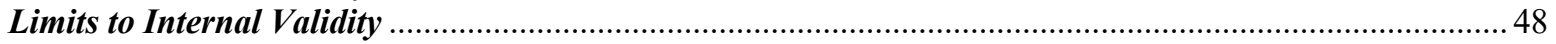

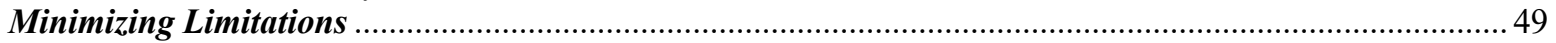

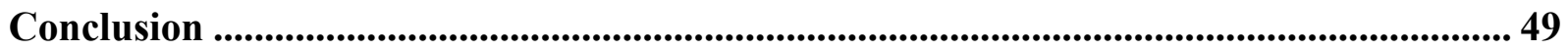

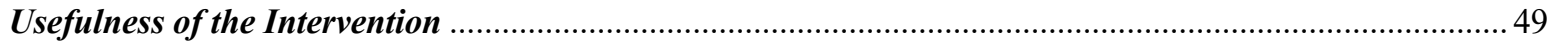

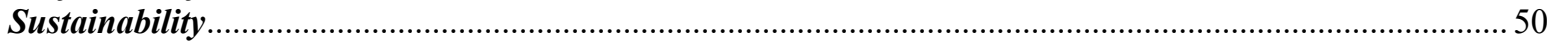

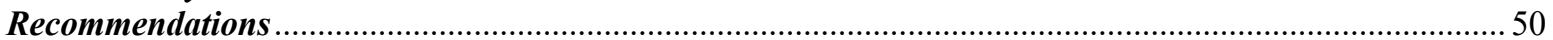

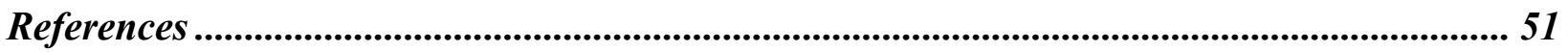




\section{Implementation of a Nonverbal Scrub Cap Identification System to Improve Communication and Perception of Patient Safety Among Unfamiliar, Deidentified Staff Members in the Operating Room}

Errors in communication are a threat to patient safety. Effective communication is hindered by factors attributed to both the sender and the receiver. In recent months, health care workers in all settings attempting to communicate have been hindered by layers of personal protective equipment (PPE) while caring for infectious patients. The coronavirus (COVID-19) pandemic has challenged staff members beyond its infectious pathophysiologic implications with physical barriers to effective communication, including filtered respirators over the nose and mouth, hooded shields, and gowns that cover frontline caregivers from head to toe. These barriers only further impeded communication and identification of team members, to the point that only eyes were visible. In an academic medical center's COVID intensive care unit (ICU), in New Jersey, staff innovated a solution and applied their name and role on PPE to improve the identification of team members.

In the operating room (OR), multiple services convene to deliver patient care. The teams of professionals include, but were not limited to, physicians, nurses, scrub technicians, medical sales representatives, and trainees. Introductions were frequently brief, and roles were not always identified, and although team members wear identification (ID) badges, they were usually covered by OR gowns and other routine PPE. Mehrabian, developed the 7-38-55\% Communication Rule Theory referencing verbal communication accounts for $7 \%$ of the intended message, $38 \%$ accounts for tone, and $55 \%$ focuses on facial and nonverbal aspects (Lapakko, 1997). The purpose of this Doctor of Nursing Practice (DNP) project investigated whether a simple nonverbal intervention to apply surgical tape identification of name and role with 
permanent marker to a scrub cap could improve identification and communication among OR team members.

\section{Background}

\section{Problem Description}

This Doctor of Nursing Practice (DNP) project was implemented at an academic learning institution that provided an opportunity for advanced practice nursing scholars to determine root causes of communication breakdowns to reduce the occurrences of miscommunication among unfamiliar, de-identified team members. Clear and complete communication between the healthcare team are prerequisites for safe patient care and key aspects in the Joint Commission's (JC) 2008 National Patient Safety Goals for Long-Term Care (Tija et al., 2010). Medical errors related to ineffective communication accounted for $60 \%$ of sentinel reported to the Joint Commission (Tija et al., 2010).

The JC requires all personnel to wear ID badges in every practice environment, though badging is not a flawless solution of staff identification. ID badges are currently utilized by OR personnel for ease of identification. However, IDs can be ineffective in sterile environments such as the OR where team members are dressed in PPE and IDs are covered. Badges are a patient safety concern due to the possibility of bacterial contamination increasing the risk of infection (Hogue et al., 2017). Badges dangling from scrub tops may cause corneal abrasions and other facial injuries specifically for anesthesia providers that work at the head of the bed in the operating room (OR). To prevent these injuries, many anesthesia practitioners wear badges at the hip level. However, the hip location obscures the badge from vision of other staff members in the OR. 
Many badges fail to express rank (Hogue et al., 2017). In addition to patient safety issues, training hospitals educate all experience levels within nursing, surgical, ancillary, and anesthesia departments which can hinder identification and mistake "rank" confusion (Bodor et al., 2017). Medical trainees can disrupt performance evaluations and team morale and even potentially impair delivery of quality care when miscommunication errors proliferate (Bodor et al., 2017). Patient care improves when teams of various medical professionals can effectively communicate by acknowledging names, roles, and responsibilities of each team member (Bodor et al., 2017).

\section{Problem Statement}

Ineffective verbal communication and factors that impede nonverbal communication, such as PPE worn by team members in the OR make it difficult to identify the name and role of other members of the OR team, which leads to communication breakdowns and potential threats to patient safety.

\section{Available Knowledge}

A literature search was guided by the population, intervention, comparison, outcome, time (PICOT) process (Rosswurm \& Larrabee, 1999). The PICO(T) question was: “Among unfamiliar, de-identified interdisciplinary healthcare team members, does the use of a simple scrub cap identification system increase team member's acknowledgement of role and name identification to improve communication breakdowns?"

\section{Search Strategy}

A comprehensive literature search was conducted in conjunction with expert opinion from the university's librarian. The electronic research of databases included: EBSCO HOST, Cumulative Index of Nursing and Allied Health Literature, Pub Med, as well as the Google Scholar search engine followed the Rosswurm \& Larrabee (1999) framework. The initial search 
limiters included publication in the past ten years (2010-2020), English language, and all publication types. Smart text searching incorporated keyword search combinations of the following terms: "nonverbal communication strategies", or "PPE", or "name badges", or "identification badges", or "identification in the operating room", or "communication challenges" on all databases. Exhaustion of these databases and search engines yielded zero evidence-based best practice publications or clinical practice guidelines pertaining to a nonverbal scrub cap identification strategy. The gap in the literature led to pursuing an expert librarian opinion.

The literature search transitioned to lower-level evidence that was produced on the topic. Only two nonexpert journal articles were discovered that directly pertained to a nonverbal identification system utilizing name and role scrub cap systems. Following expert guidance, search results were expanded to understand the importance of communication among interdisciplinary team members. Search terms included "poor communication in the OR", or "communication related sentinel events", or "JC requirements" to further support the need for research pertaining to this quality improvement (QI) project.

\section{Critical Appraisal of Literature}

The exhaustive review of the literature yielded 1 randomized control trial (RCT), 3 descriptive studies, and 2 non expert opinion articles. Relevant and analogous studies were chosen to use as a guide to pilot the project due to the lack of previous research pertaining to a nonverbal scrub cap identification system.

Stone's (2019) nonexpert opinion argues that a simple idea, such as placing one's name and role on their scrub cap can produce profound effects when improving patient care. Stone (2019) documented a viral idea known as the \#theatrecapchallenge. The unprecedented concept 
was derived from Dr. Hackett, an Australian Anesthetist. The concept explored the use of labeling OR team member's surgical caps with their name and role to eliminate a perceived problem in communication breakdown in the OR (Stone, 2019). This novel method was derived without academic evidence but was developed and implemented as a trial-and-error scenario prior to being published in social media (Stone, 2019).

The Patient Safety Network (PSN) critiqued Stone (2019), highlighting that Dr. Hackett's intervention was not supported by research due to the omittance of data. The article described attempts to discover the research behind Dr. Hackett's informal framework but was unsuccessful as this concept was not performed as a research trial. Qualitative data was obtained through communication surveys. However, the type of survey, implementation site, inclusion and exclusion criteria were not disclosed. The presented argument concurred with Stone's (2019) support of the intervention that was analyzed from data received from the surveys (Patient Safety Network [PSN], 2019). A synopsis stated that $70 \%$ of adverse events were reported from a communication error as compared to $30 \%$ when staff's name and role were clearly displayed. PSN (2019) produced supporting data for improved patient care when nonverbal communication strategies were used in the OR while dressed in PPE. However, the reliability, validity, and credibility were not supported through a peer reviewed study.

Jung et al. (2018) performed a double-blind RCT to determine the subconscious response humans place on their birth name as compared to a pronoun. Inclusion criteria endorsed 20 to $70-$ year-old females enrolled in breast cancer surgery over a one-year span (2014-2015) (Jung et al., 2018). Exclusion criteria included women who did not speak Korean, had any health-related comorbidities, or were hearing impaired (Jung et al., 2018). The aim of the trial provided statistical evidence of awakening post anesthetic delivery through the utilization of a patient's 
given name compared to a pronoun such as "ma'am, wake up" and "sir, wake up" (Jung et al., 2018). The conclusion infers a statistical significance in patients' response after utilizing the patients' given name in comparison to a pronoun. The mean standard deviation (SD) time was 337 seconds (154) when using the patients' name and $404(170)$ when using a pronoun ( $\mathrm{p}=$ 0.041). The evidence produced data to suggest the importance that humans place on their own given name and recommends a proper name should be utilized whenever possible. This project further supports the need for utilizing proper names in the OR to enhance effective communication.

Caprice et al. (2007) conducted a descriptive study which reviewed 444 surgical malpractice claims and identified 60 of the 81 total cases related to communication breakdowns. Inclusion criteria required a closed malpractice claim among surgical patients. Incident reports were analyzed through the $\mathrm{JC}$ to determine the root cause of adverse events which led to malpractice claims. These reports were then categorized based on root cause. Two surgeon physicians analyzed the data to distinguish patterns, associated factors, and possible causes of communication breakdowns (Caprice et al., 2007). The majority (92\%) were verbal communication breakdowns involving 1 transmitter and 1 receiver (64\%). Attending surgeons were noted to be the most common team member involved. Status asymmetry (74\%) and ambiguity regarding responsibilities (73\%) were common factors involved in handoff breakdown $(43 \%)$ in addition to transfer of care $(39 \%)$. Failure to notify the attending surgeon of critical events and failure of attending-to-attending handoffs were the most common finding. Caprice et al. (2007) claimed the intervention could prevent $45 \%$ to $73 \%$ of communication breakdown malpractice claims. 
A descriptive study conducted by Rosen et al. (2019) emphasized the importance of nonverbal communication among OR staff. This study introduced a role-based color-coded headcovering system in an attempt to reduce misidentification of individuals in the OR. Data collection relied on pre-assessment surveys 1 month prior to the intervention. Post-intervention surveys were assessed 2 months after implementation $(\mathrm{N}=28)$ to assess the surgical team's perception on misidentification in the OR. The study found a $37 \%$ increase of staff members who perceived an improvement in role recognition among physicians and students $(\mathrm{p}=0.007)$.

Bodor et al. (2017) released a descriptive study pertaining to communication failures among multidisciplinary personnel's efficiency, performance, and morale in an OR setting. The sample size included 50 OR team members composed of 18 surgeons, 14 anesthesiologists, and 18 nursing members to assess name and rank importance. Results concluded each individual service reliably knew their own team members' names and rank. However, surgery and anesthesia teams displayed decreased identification between experienced staff and lower-level trainees. In contrast, nursing teams identified all levels and performed better in name and role recognition. Basic identification was hindered among multidisciplinary surgical team members. Misidentified participants were typically lower-level residents working among supplementary services. All survey respondents reported the need to improve identification among staff members and suggested incorporation of a viable sterile name and rank badge in addition to a proper self-verbal identification. (Bodor et al., 2017).

\section{Literature Review Synthesis}

The evidence and method distinctions preceded the synthesis of results. Two studies incorporated Dr. Hackett's novel nonverbal scrub cap intervention but lacked a formal feasible framework (Stone, 2019; PSN, 2019). Two descriptive studies identified the importance of 
nonverbal communication strategies to determine role recognition within the OR (Rosen et al., 2019; Bodor et al., 2017). Another descriptive study examined malpractice considerations derived from communication breakdowns (Caprice et al., 2007). One RCT study revealed the importance in proper name utilization (Jung et al., 2018).

All sources supported the proposed topic but differed among objectives and methods. Effective communication in the healthcare setting was a robust finding in the literature search (Stone, 2019; PSN, 2019; Jung et al., 2018; Caprice et al., 2007; Rosen et al., 2019; Bodor et al., 2017). However, only four of the six sources produced statistically significant data (Jung et al., 2018; Caprice et al., 2007; Rosen et al., 2019; Bodor et al., 2017). Methods of literature incorporated three descriptive studies (Caprice et al., 2007; Rosen et al., 2018; Bodor et al., 2017), one randomized control trial (Jung et al., 2018) and two informal frameworks guided the project formation (Stone, 2019; PSN, 2019). Most of the studies assessed perceptions on communication breakdown among staff members (Stone, 2019; Caprice et al., 2007; Rosen et al., 2019; Bodor et al., 2017).

The concept of a scrub cap identification system were specifically mentioned among three sources (Stone, 2019; PSN, 2019; Rosen et al., 2019). One study examined the impact on name recognition (Jung et al., 2018). Five sources examined nonverbal communication strategies (Stone, 2019; PSN, 2019; Rosen et al., 2019; Bodor et al., 2017). Two sources addressed the informal framework built on the implementation of a scrub cap identification system (Stone, 2019; PSN, 2019). One source explored the impact on verbal communication (Jung et al., 2018). All six sources addressed patient safety pertaining to communication breakdowns, regardless of the communication strategy (Stone, 2019; PSN, 2019; Jung et al., 2018; Caprice et al., 2007; Rosen et al., 2019; Bodor et al., 2017). 


\section{Rationale}

\section{Theoretical Framework}

The theoretical framework to guide the QI project was based on Lewin's Change Theory (Shirey, 2013). The 3-step model consists of the unfreeze stage, changing stage, and the refreeze stage (Shirey,2013).

In the unfreezing stage, Lewin recommends that a perceived change is identified and needed within a system (Shirey, 2013). For the project, communication breakdowns have been reported to the JC due to ineffective communication among staff members (Tija et al., 2010). Communication breakdowns can be disastrous to safe patient care (Dingley et al., 2008). To elicit change, a communication enhancement strategy was created. A nonverbal scrub cap identification system intervention was utilized to assess staff's perceptions pertaining to patient safety and effective communication among interdisciplinary staff members in the OR while dressed in PPE.

Throughout the changing phase, one would look at the problem that was identified in the first step, formulate a plan to solve the problem through altering behavior, and then implement the change (Shirey, 2013). In relation to this project, the cystoscopy ORs in an academic teaching hospital provided the opportune setting for unacquainted OR members to place their name and role on a piece of tape to be displayed on the ventral side of their scrub cap. The plan included the usage of this nonverbal communication strategy by all members entering the assigned OR to evaluate communication among staff members and a perceived effect on patient care.

The final step is known as the refreeze stage, which occurs when the change has been implemented, adopted, and the new behavior becomes the standard (Shirey, 2013). Outcomes of 
the QI project will be examined to determine if this identification technique improved team members communication during the intervention. At the conclusion of the project, the OR manager will be notified to potentially implement a practice change to enhance patient safety.

\section{Specific Aims}

\section{Purpose}

The purpose of this project is to implement a simple scrub cap identification system in an academic medical center operating room on a trial basis to:

1) Determine the effect of a name and role identification intervention on staff's perceptions of patient safety.

a. Staff's perceptions of patient safety

b. Prevention of any intraoperative errors

2) Determine the effect of a name and role identification intervention on team performance among unfamiliar, de-identified team members dressed in OR PPE.

a. Rate of "somewhat" and, or "strongly agree" to enhanced communication

b. Rate of proper role identification

\section{Methods}

\section{Context}

This project setting involved the 4 urological ORs at a 700-bed academic teaching hospital in West Virginia (WV) that performs more than 400 minimally invasive, roboticassisted urological procedures each year in addition to many other urologic services (WVU Medicine, 2020). The population of interest included all nurses, physicians, anesthesia providers, scrub technicians, students/ trainees, medical sales representatives, and any other member that 
would directly enter the project approved OR, which was conducted between February and March of 2021.

\section{Intervention}

\section{Alignment of the Intervention with Specific Aims}

The project took place over three phases. Phase 1 consisted of the pre-implementation phase where the project design was created, developed, and proposed. Phase 2 consisted of the implementation phase of the intervention where participants placed their names and roles on their scrub caps and provided feedback using pre- and post- surveys. Lastly, phase 3 , termed the post-implementation phase, consisted of data collection, analysis, and dissemination.

Specific aim 1: In order to determine the effect of a name and role identification intervention on staff's perceptions of patient safety, the project leader supplied each OR with surgical tape, permanent marker. The project leader requested participants to affix their name and role with surgical tape onto the outside of their scrub caps prior to entering the room. Additionally, the project leader educated the OR Registered Nurses (RNs) at a monthly staff meeting on the importance of their role to inform staff entering the urological ORs to participate. In efforts to reach absent staff members, a poster was created by the project leader and placed in the hallway immediately outside the OR.

The project leader intended to e-mail all OR staff to disseminate Qualtrics based pre- and post-surveys. However, e-mailing all OR staff was not feasible due to information technology constraints. As a resolution, paper surveys were provided to all OR staff. Surveys were sent to the anesthesia department by the Chief CRNA on the project leader's behalf. The e-mail contained the same details discussed in the OR staff meeting and provided links to the pre- and 
post-surveys for their convenience. A convenience sample of at least 5 participants assigned to each urological OR per day was expected over the 2-month timeline.

Participants received a 9-question pre-survey accompanied with an 8-question postsurvey utilizing a 5-point Likert scale. Pre-surveys (see Appendix A) obtained data evaluating the role of the participant, frequency working in the urological specialty, previous adverse events, identification difficulty while wearing PPE, impact on patients' safety, common introductory practices, and the perception of communication of staff member's names and roles on team performance. Post-surveys (see Appendix B) asked participants, their assigned role and frequency working in the urological ORs, identified and de-identified staff members, the perception of the intervention's impact on the enhancement of communication and patient safety, in addition to, an inquiry for practice change. No valid or reliable tool could be found in the literature search, so tools had to be developed for this intervention which included the pre- and post-surveys. Tools were developed in consultation with the DNP project team and deemed valid for this project.

The project leader prepared 4 sets of color-coded folders labeled "pre-surveys", "postsurveys" and "completed surveys" and placed one set in each of the 4 different participating urological ORs. Tape and markers were obtained from the hospital's central supply and were visible near the folders along with laminated reminders of the project. RNs were encouraged to recruit participants to complete pre-surveys and to present available supplies such as tape and a marker. Survey completion depended on the RNs encouragement at onset and cessation of the case. The project leader collected the anonymous paper surveys weekly and reprinted paper surveys for each room with a low supply to ensure an adequate number of surveys were available to participants. At the end of the two-month span, all equipment was gathered from the 4 
participating ORs. The data was manually inputted into the online Qualtrics database for transfer to SPSS software.

Specific aim 2: In order to determine the effect of a name and role identification intervention on team performance among unfamiliar, de-identified team members dressed in OR PPE, participants rated their level of agreement on the perception of enhanced communication through pre- and post-surveys. The survey tool measured the success of this objective when at least $50 \%$ of participants responded "strongly agree" or "agree" to knowing each staff member's name and role while in the OR enhanced team performance. The second objective was measured utilizing the post-survey responses. The objective was achieved if $50 \%$ of participants responded "strongly agree" or "somewhat agree" to a nonverbal identification system displaying roles on scrub cap enhanced communication among the OR team. Participants were asked to indicate the individual or set of staff members that were unidentifiable in the OR to further determine if the second aim was achieved.

\section{Benchmarks}

The concept of a nonverbal scrub cap identification system derived from the obstacles experienced during the COVID-19 pandemic and parallels the Healthy People 2020 global health initiative to "improve public health and strengthen United States national security through global disease detection, response, prevention, and control strategies" (Healthy People 2020, 2020). In conjunction with the support of the literature, increasing effective communication, a control strategy that advanced practice nurses can adopt to align with this response initiative (Healthy People 2020, 2020). 


\section{Gaps in the Evidence}

Previous studies examined the role of communication in healthcare settings, but a gap in academic literature was identified regarding the use of a scrub cap identification system among staff members while dressed in OR PPE.

\section{Congruence with the Organization's Strategic Plan}

The mission statement at the implementation site states: "to improve the health of West Virginians and all we serve through excellence in patient care, research, and education" (West Virginia University [WVU] Medicine, 2020). Aligning with the vision of the institution, "to transform lives and eliminate health disparities through a nationally recognized patient-centered system of care that includes: Development of new approaches to improve healthcare, including team-based models of care, expanding West Virginia University (WVU) clinical and translational research" (WVU Medicine, 2020). The implementation of a nonverbal scrub cap intervention aimed to reduce health disparities by enhancing interdisciplinary communication and improve patient safety, thus aligning with the hospital's mission.

\section{Technical Equipment and Instruments}

Electronic Qualtrics surveys were an option to complete the pre- and post-surveys, but the majority of participants chose the paper format. Utilization of technical equipment was minimal. A PowerPoint presentation was created for educational purposes and presented at the monthly staff meeting which was viewed from staff member's personal computers or phones. Project reminder cards were printed by the project leader and placed on the RNs desk for accessible reference. 


\section{Key Personnel}

Key personnel included the project leader, Keri Adams, and a key consultant, Dr. Chad Crigger. The stakeholders included the urological OR staff members participating in the QI project. Nicole Whitlock, the OR Manager, gave administrative support to conduct the intervention in the OR at the local academic teaching hospital. Expert opinion was valued from the faculty of record (FOR) and the university's statistician.

\section{Technology}

The proposed intervention required minimal technology for participation. E-mails sent to the anesthesia department summarized a PowerPoint presentation launched by the project leader at a monthly staff meeting. Printed pre- and post-surveys were provided for convenience to overcome the observed lack of computer access while in the OR.

\section{Budget}

As part of a feasibility analysis, a budget plan for the project was created (see Appendix C). A principal strength to this DNP project is the low-cost analysis upon implementation. Exact figures were unable to be disclosed from the hospital. Thus, a general cost analysis search was conducted. Anticipated expenses were negligible and included the expense of surgical tape, disposable surgical caps, and a Sharpie marker. The price of 3M Micropore surgical tape is $\$ 0.39$ per roll and a box of Sharpie markers ranged from $\$ 3.00$ to $\$ 6.00$ from Amazon. Supplies for the project provided by the hospital's central supply and thus readily available within the OR setting. Standard PPE such as scrub cap bouffants were provided by the facility as part of their required OR attire and did not impact PPE consumption. The OR participants did not receive any additional financial compensation, only their pre-approved hourly wage. No additional compensation was given during the project. The projected costs were minimal in comparison to 
the billions of dollars that communication errors cost organizations, making a financial return on investment more likely (Kern, 2020).

\section{Evidence of Key Site Support}

The primary stakeholder is Dr. Chad Crigger and Nicole Whitlock, who have expressed interest in the project. Additional stakeholders include the OR participants as the intervention can directly pertain to their individual practice.

\section{Evaluation Plan}

\section{Assessing the Impact of the Intervention}

The impact of this DNP project assessed data collection from pre- and postimplementation surveys. The pre- and post-surveys assessed staff's perception of patient safety in addition to their perception on team performance and enhanced communication. The presurvey design gained knowledge on the participant's experience related to adverse events to further support the purpose of this project. The survey tools assessed the correlation of a nonverbal scrub cap identification system on the impact of patient safety through statistical analysis utilizing a Mann-Whitney $U$ Test. An unpaired, Mann-Whitney $U$ test, was chosen to statistically determine the difference between the ordinal variables for two independent groups. A Likert scaled post-survey design assessed communication by determining if more than half of the participants marked "strongly agree" or "agree" to the perception of enhanced team communication related to the intervention. A Likert scaled survey design measured the longevity of the project to evaluate the sustainability of the intervention.

\section{Project Objectives: Correlation between Project Outcomes and the Intervention}

The first project objective evaluated the impact of a nonverbal scrub cap identification system on staff's perception of patient safety among unfamiliar, de-identified team members 
dressed in OR PPE. A hypothesized theory for this DNP project mentioned the use of a nonverbal scrub cap identification system displaying name and roles on scrub caps will improve the staff's perception of patient safety. The collection measures to obtain data were through preand post- surveys. A Man-Whitney U test was performed to determine if the evidence-based measure of the participant's perception of patient safety was achieved due to this intervention.

The second project objective hypothesized the use of a nonverbal scrub cap identification system, displaying names and roles on scrub caps, will enhance communication among unfamiliar, de-identified staff members donned in OR PPE. The evidence-based measure of the perception of enhanced communication on team performance was verified when more than half of participants responded, "agree" or "somewhat agree" to the intervention's impact on communication. Another outcome/measure was proper role identification. Data was collected using the pre- and post-surveys to determine the individuals that were reported unrecognizable. Additionally, exploring the sustainability of a practice change was measured by a Likert scaled post-survey results yielding "extremely willing" or "somewhat willing" to actively adopt this QI project into practice.

\section{Strategies to Achieve the Specific Aims}

The specific aims of this project focused on the effect of a name and role identification intervention on staff's perceptions of patient safety. A secondary aim intended to determine the effect of a name and role identification intervention on team communication among unfamiliar, de-identified team members dressed in OR PPE. Strategies incorporated the use of education, flexibility, and open communication.

The first aim focused on staff's perception on patient safety. Prior to the start of the project, the project leader participated in a clinical rotation at the intended site and openly 
communicated with other staff members to gain knowledge pertaining to improve nonverbal communication strategies among unfamiliar, de-identified staff members. The project leader considered suggestions to formulate a proposed project to meet the specific needs at the academic teaching facility. The project leader led an educational session on a nonverbal scrub cap identification system and adjusted the project when adversities arose.

Throughout the dynamic implementation phase, the project leader openly communicated with OR RNs to assess improvements to the project. Through collaboration, the project leader was made aware that 2 staff members missed the backside of the survey. The project leader reprinted the surveys onto two stapled pages to improve survey compliance and to minimize this event from recurring.

The second aim intended to monitor staff's communication among unfamiliar, deidentified team members. Prior to the start of the project, the project leader participated in a virtual staff meeting to educate participants on the importance of monitoring communication while in the urological ORs. Emphasis was placed on the importance of documenting these perceptions through the pre- and post-surveys that were measured through Likert scaled responses. Prior to the start of the project, reminder flyers were placed on the OR RN's desk to ensure the team's awareness of the project which was essential to participation. Open communication and education were paramount to the success of data collection. The project leader attempted to verbally remind the OR RNs to encourage participation by providing the necessary project tools at the beginning of the case. The project leader openly communicated with staff members in the urological ORs and educated staff members that reported their absence to the staff meeting. During the intervention, the project leader collected paper surveys while 
monitoring online responses to assess participation and ensured paper copies were plentiful for ease of participants compliance.

\section{Measures}

\section{Measures for Studying Processes and Outcomes}

Measures utilized for data analysis have a basis in pre-and post-intervention surveys responses from all members of the urological OR team which include: nurses, physicians, anesthesia providers, scrub technicians, students, medical sales representatives, and those that identified as "other". The project design followed Dr. Hackett's informal framework was modified to include pre- and post-surveys to assess the interventions effectiveness. Validity and reliability of the project and its measures were established through a priori consultation with the project team. Expert opinion from the university's statistician was valuable. Comparative analysis of the outcomes related to participant's perception of the intervention's effect on patient safety was through the recommendation of statistical analysis using a Mann-Whitney UTest. A Likert scaled survey-design obtained data pertaining to enhanced communication on team performance.

\section{Contextual Elements: Success.}

Participants buy-in was a contributing factor to the project's success and data analysis. The current process of hospital issued identification badges were required per hospital policy but not always visible while in an OR. This circumstance provided an opportunity for the project leader to improve the process by placing the participants name and role on an easily visible portion of their uniform. Key stakeholders, such as Nicole Whitlock, provided an avenue for the project leader to educate OR staff members at a virtual staff meeting. Dr. Chad Crigger provided full support, approved the project in the urological ORs, and disseminated the project's goals and 
expectations to the urological department. Additionally, the chief CRNA provided full support and forwarded the project leader's PowerPoint presentation to the anesthesia department via email.

\section{Contextual Elements: Limitations}

A main limitation to the project was the logistics of communicating with hundreds of staff members in a large academic teaching hospital. The project leader notified OR team members on the project's expectations, but due to time constraints, vacations, and call offs, every member could not be educated, which may have inhibited participation. Data results may have been impacted due to the smaller, urological hired OR staff participating daily compared to the general surgical ORs.

Another limitation exposed from a participant was the impact on burn out from rapid policy changes due to the repercussions of COVID-19. Participation was strongly influenced by the OR RNs willingness to provide the project's resources to participants. When speaking with staff members, some participants felt increasingly overwhelmed and declined to volunteer for additional tasks that would add to their preexisting daily requirements. Initially, buy-in from hospital management proved challenging due to the misconception that additional PPE would be required. Once it was explained that tape could be added to existing scrub caps, management fully supported the project.

\section{Contextual Elements: Efficiency}

Qualtrics surveys were e mailed to the anesthesia department by the Chief CRNA, but disseminating a mass e-mail to hundreds of staff members proved cumbersome for an already busy OR administration. E-mails to the organization were firewall protected and the project leader lacked access to the participants e mail addresses, thus, paper pre- and post-surveys 
proved to be advantageous to the efficiency of obtaining data. To overcome the informational technology (IT) barrier, paper surveys were conveniently placed on the OR RN's desk for completion at the cessation of the case. The urological-hired OR staff members completed the project daily because of their consistent exposure to the project. The project leader was present weekly due to personal clinical rotation as so was able to ensure surveys were completed, collected, and stocked additional supplies when necessary.

\section{Contextual Elements: Costs}

This DNP project did not require major financial costs as the materials were obtained from the hospital's central supply. Monetary investment was negligible and marketing supplies for the poster cost the project leader $\$ 15.00$.

\section{Methods to Assess Data Completeness and Accuracy}

Methods involved with data completeness and accuracy included consultation with a statistician to discuss data collection and analysis. The pre- and post-surveys were designed to gain knowledge on past, current, and potential future practices of a nonverbal communication strategy that impacts patient safety and team communication. Pre- and post-surveys included explicit directions for "select multiple" or "select one" answer responses. During data analysis, 11 surveys provided qualitative information to explain multiple selections opposing the Qualtrics platform which was designed for a single selection. Due to this unexpected event, the statistician advised removing the surveys from the data to minimize skewed results. Participation was voluntary and participants could omit responses to questions but could only respond with multiple selections on specifically instructed questions. Only the surveys with multiple responses, instead of omitted responses, were discarded per the advice from the statistician. To 
ensure accuracy and minimize human error when transcribing the paper surveys to the electronic software, the data set was inputted twice, and no discrepancies were found.

\section{Analysis}

Statistical analysis was obtained through pre- and post-intervention survey responses. The pre-survey design incorporated 9 questions that distinguished: the assigned role of the participant, the frequency working in the specialty, the effect of adverse events to patients due to the lack of communication, the perception of identifying members under PPE, the perception of distinguishability on patient safety, common practice to identify others, and methods of introduction. The survey design incorporated demographic, binary, and ordinal data. Variance was calculated when analyzing the statistical deviations of enhanced communication while comparing it to the mean.

The 8-question post-survey incorporated similar questions, such as, the participant's role and frequency of working in the specialty. Additionally, the survey aimed to discover the least recognized members in the OR. A similar Likert scaled question was utilized in the post-survey to discover the perception of the intervention's enhancement of patient safety. Lastly, the postsurvey evaluated sustainability, requesting participants to rank their willingness to change their individual practice. To conclude, the post-survey included a qualitative response where participant's opinions were valued to improve future projects.

Statistical analysis was conducted through SPSS software and in consultation with the university's statistician. A Mann-Whitney $U$ Test was performed to compare nonpaired dependent variables from the pre- and post-intervention survey to assess participant's perception of enhanced patient safety. Results were referenced as statistically significant with a p value 
$<0.05$. This test was selected to compare unpaired, ordinal data resulting from a 5- point Likert scale survey design.

\section{Ethical Considerations}

Approval was obtained through the WVU Institutional Review Board (IRB) and cited as a DNP Project. Endorsement was obtained prior to implementation of this quality improvement project. The risks to subjects was minimal as the project did not involve patient participation or human research. The data collection was private, confidential, and participants were able to withhold information without their survey being discarded. Participants could choose to forego participation on the intervention date. The project leader ensured that IRB approval was on file and provided participants with sufficient knowledge via e-mail and virtually at a monthly staff meeting for participants to make an informed decision prior to participation. All data was protected and locked on the project leader's private computer that is password protected to adhere to IRB requirements and paper surveys were unidentifiable and not participant specific.

Ethical principles such as respect for persons, beneficence, and justice were the foundation of the project design and were not violated under any circumstance. Conflict of interest was minimized by ensuring unbiased data from participants by encouraging individual thoughts regardless of response to the intervention. The project's risks were minimal in comparison to the benefits of the project. IRB approval was obtained, and all aspects were followed as outlined. The project leader is invested in the project and has conducted the QI project without competing interests such as institutional influences or financial gain.

\section{Results}




\section{Results}

\section{Evolution of the Intervention}

As part of the feasibility analysis a projected timeline was generated (see Appendix D). The draft for the DNP proposal was commenced in the summer of 2020 and edited in sequential courses throughout the nurse anesthesia curriculum. IRB approval was sought in the fall of 2020 and officially obtained in the spring of 2021. Upon committee approval and prior to the implementation date, key stakeholder meetings were conducted during the fall and spring of 2021. The original intention provided all OR staff members with electronic surveys via e-mail, but adjustments were made due to IT firewalls, thus printed surveys were provided. The intervention spanned 2 consecutive months and concluded in April of 2021. During the implementation phase, the project leader monitored participation weekly by collecting paper surveys and noticed the lack of participation in the general surgery OR as compared to the permanent urological ORs. Consequently, 0 surveys were analyzed from this room. September 2021 marked the beginning of data analysis and the post-implementation phase. The DNP manuscript was drafted, and a poster presentation was submitted to the WV State American Association of Nurse Anesthesiology meeting held in October of 2021.

\section{Process Measures and Outcomes}

The process measures and outcomes utilized pre- and post-intervention surveys to gauge the specific aims and outcomes. The pre- and post-intervention surveys intended to gain demographic, binary, and ordinal data from participants to provide statistical analysis on the perception of patient safety. Data was analyzed using a Likert scale assessment of the effect of the intervention on staff's communication among unfamiliar, de-identified staff members. A 
Mann-Whitney $U$ Test (see Appendix E) was conducted to compare the pre- and post-survey questions pertaining to patient safety.

A total of 48 paper formatted pre-surveys and 3 electronic Qualtrics surveys were analyzed. A sum of 11 paper pre-surveys obtained were dismissed due to multiple selections or qualitative justifications to the single select questions.

Pre-intervention: The pre-intervention results (see Appendix F) included 17 responses from nurses (33.33\%), 8 physicians (15.69\%), 8 anesthesia providers (15.69\%), 5 scrub technicians $(9.80 \%), 6$ students/trainees $(11.76 \%), 0$ medical sales representatives, and 7 other (13.73\%) which were listed as, "CST II," "RA-C," "X-ray technician," "resident physician," “on-site Stryker," and "laser operator."

\section{Figure 1}

Outcome measures to determine participants' roles

\section{PRE Q1: WHAT IS YOUR ASSIGNED ROLE IN THIS PROCEDURE?}

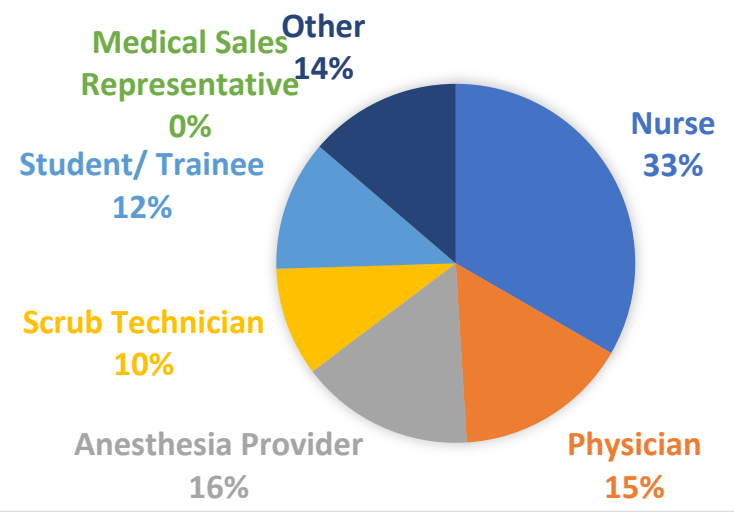

Note. Ordinal data was collected to rank roles.

Frequency working in the urological setting was asked by, "How frequently do you work in this urologic specialty?" 6 respondents marked "rarely" $(11.76 \%), 12$ "monthly" $(23.52 \%), 10$ “weekly" (19.61\%), and 23 "daily” (45.10\%). 


\section{Figure 2}

Outcome measures assessed the participants frequency of working in the urological ORs

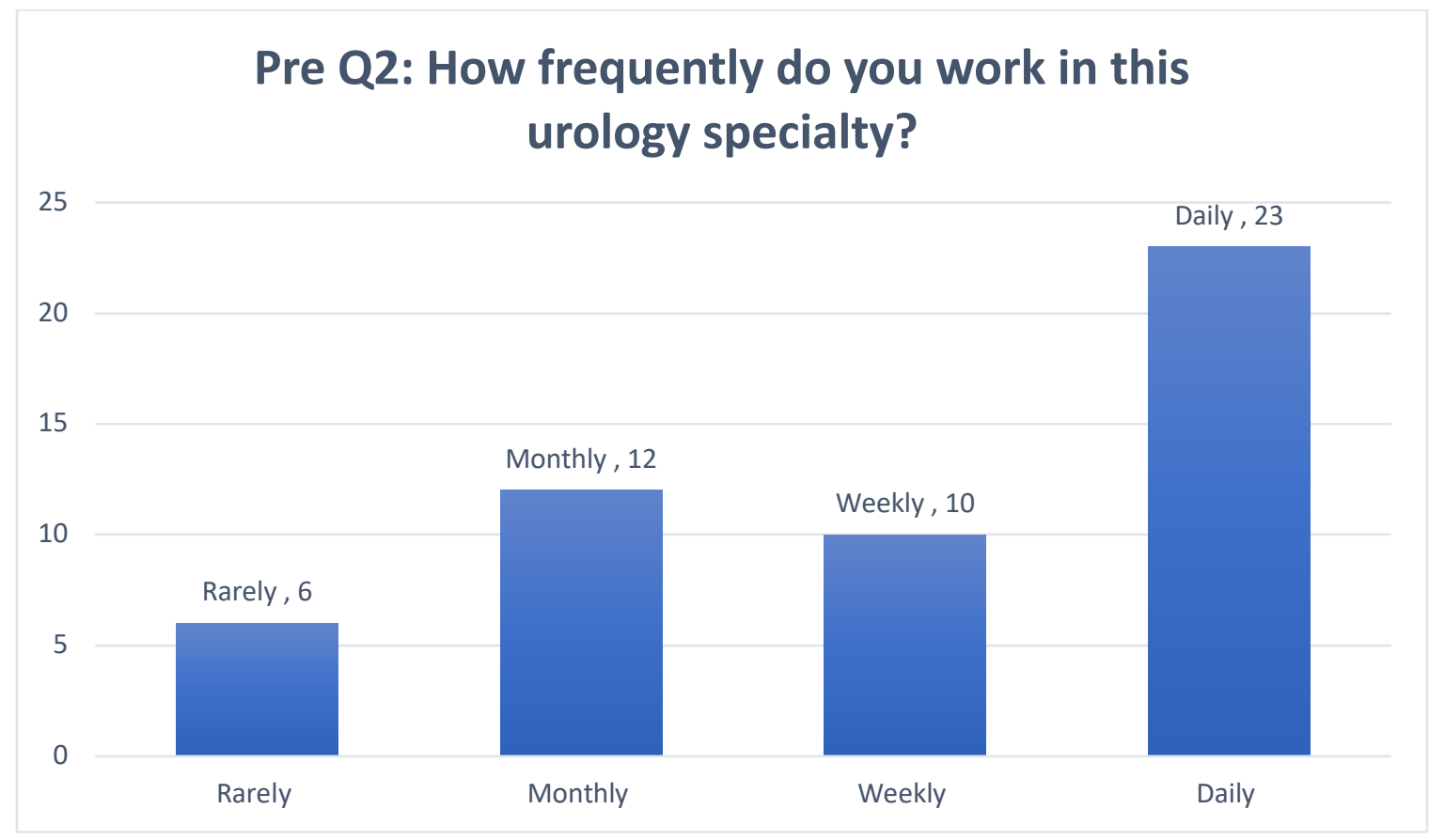

Note. The majority of survey participants reported to have worked in the urological specialty daily. The project design was created to benefit from an unfamiliar, multidisciplinary team.

Of the 51participants, 45 respondents marked "No" (88.24\%) to, "Has a patient in your care ever had an adverse event related to the inability of providers to identify each other?" 6 participants marked "yes", $(11.76 \%)$ which is a rationale for improved communication and need for this DNP project. Statistical analysis reveals that the mean for this question is 1.88 with the minimum being 1.0 and maximum being 2.0. The standard deviation was 0.32 and the variance was 0.10 .

Figure 3 
Outcome measures assessed the impact of identification on patient safety.

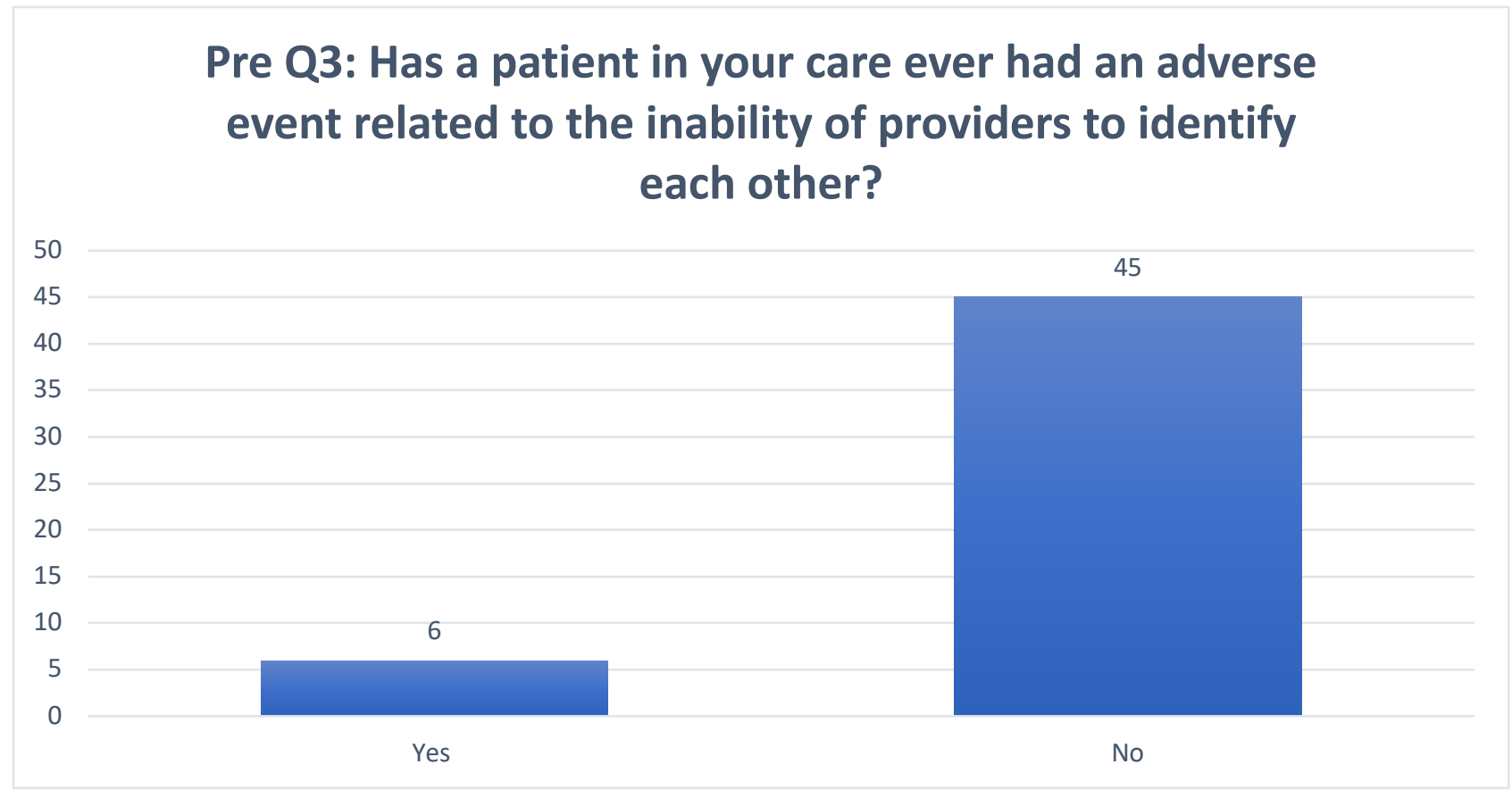

Note. Participants reported the lack of staff identification has negatively impacted patient safety.

This unexpected finding suggests evidence of chronic communication breakdowns among staff members in the OR.

"How difficult is it to identify staff members roles while fully donned in PPE?" was a fundamental question stemming from communication breakdowns noticed by the project leader from the COVID-19 pandemic. The project leader intended to gain knowledge on PPE required settings and its effect on identification where staff members wear uniformed, sterile gowns covering identification badges. 21 respondents (42\%) marked, "I find it easy to identify every member assigned to the OR," 22 (44\%) marked, "I can identify almost every member in the OR, but I do not know everyone in the case," and 7 (14\%) participants, "struggle to identify others in the OR.” A paramount finding revealed, 23 survey responses worked in the specialty daily, but only 21 reported knowing the staff to entirety. Only $42 \%$ of participants reported the ease of 
identification in the OR. The minimum value was 1.0 with the maximum 3.0 , yielding a mean of 1.72 and a standard deviation of 0.69 and a variance of 0.48 .

\section{Figure 4}

Outcome measures assessed identification difficulty while donned in PPE

\section{Pre Q4: How difficult is it to identify staff member roles while fully donned in personal protective equipment} (PPE)?

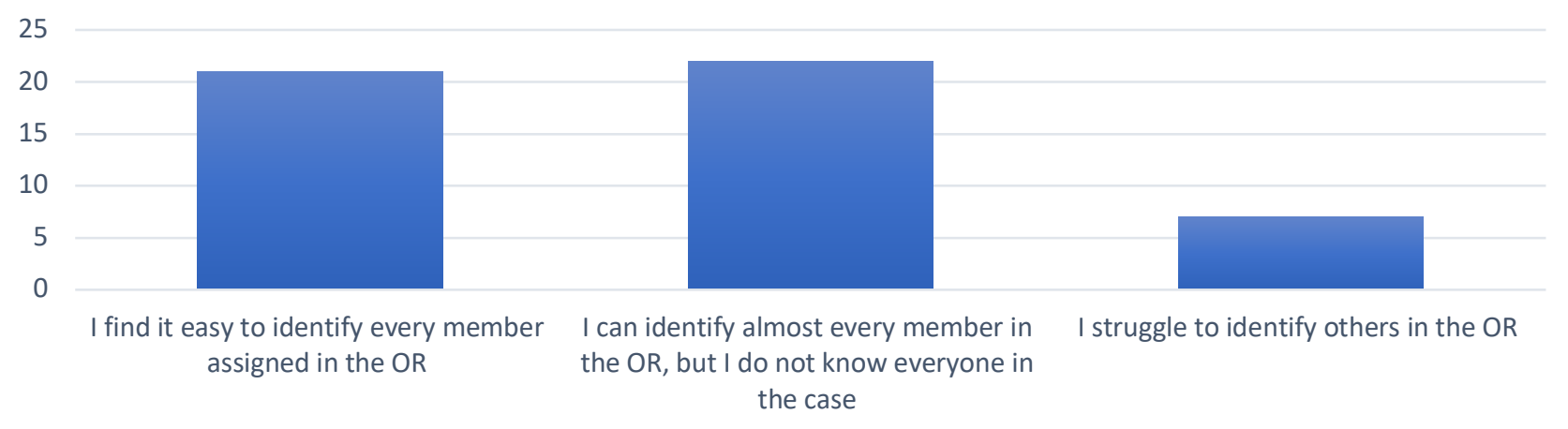

Note. The data infers that PPE can impact identification in the OR.

Binary data obtained in the pre-survey addressed a specific aim, "Do you think that being able to distinguish name and roles would help improve patient's safety?" 46 participants responded "yes" (92\%) and 4 responded, "no" $(8.0 \%)$ with the mean being 1.08 , the standard deviation 0.27 and the variance 0.07 . This question was compared using a Mann-Whitney $U$ Test to the post-survey that will be discussed in subsequent paragraphs.

\section{Figure 5}

Outcome measures on staff identification on patient safety 


\section{Pre Q5: Do you think that being able to distinguish names and roles would help improve patient's safety?}

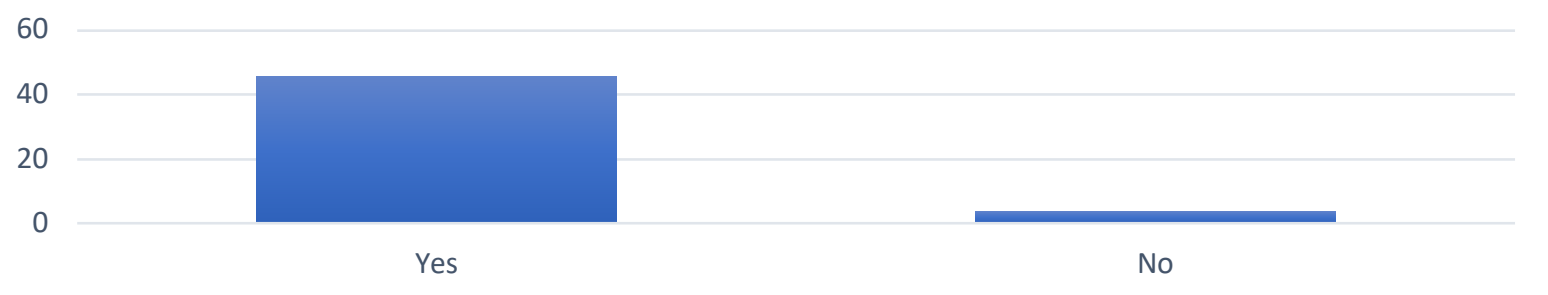

Note. Participants reported that distinguishing names and roles of staff members improves patient safety.

Question 6 of the pre-survey asked, "What is your most common practice to identify others on the OR team?" 15 survey responses (29.41\%) marked, "I know everyone's role and name in the OR" with 17 (33.33\%) responses expressed, "I ask staff members their name and role for every case." $19.61 \%$, for a total of 10 responses marked, "I look for nonverbal cues such as identification badges," and 9 (17.65\%) responses to, "I ask others if I don't know an unfamiliar team member." 0 responses $(0.0 \%)$ were indicated for "I do not seek to learn other people's name and roles." While all responses indicated that participants seek to learn other staff member's names and roles, comparative analysis revealed that only $42 \%$ of participants reported an ease of identification in the OR underscoring current challenges with common practices.

\section{Figure 6}


Outcome measures assessed participant's most common method of identification.

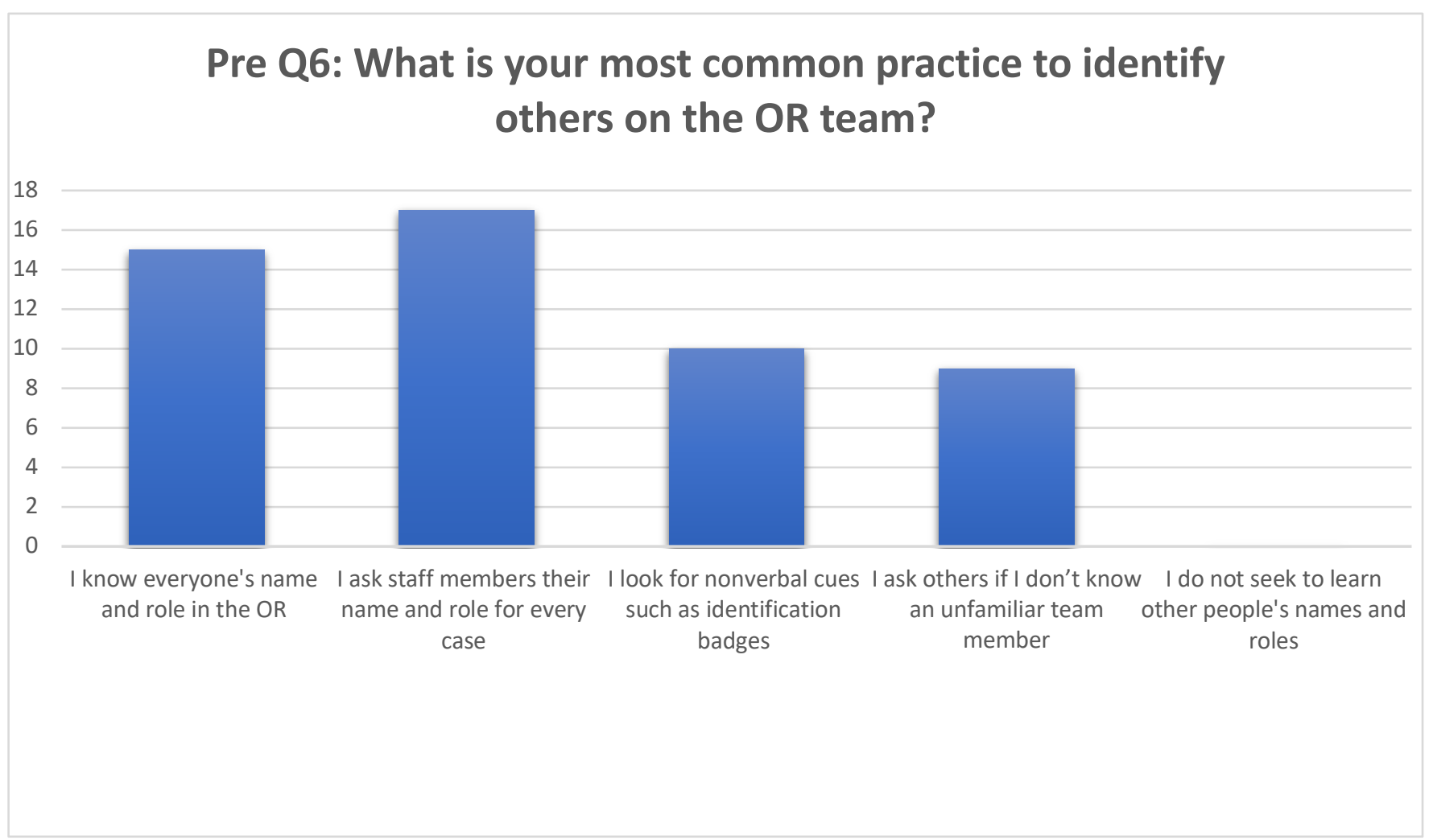

Note. Participants reported utilizing both verbal and nonverbal methods of identification.

Question 7 of the pre-survey asked, "How often do you introduce yourself to other members of the OR team?" 5 (9.08\%) marked "never," 8 (15.69\%) marked "rarely," 16 (31.37\%) marked "sometimes," $12(23.53 \%)$ marked "often," and $10(19.61 \%)$ responded "always" for a total of 51 responses. The minimum was 1.0 to a maximum of 5.0 with the mean yielding 3.27. The standard deviation was 1.22 with a variance of 1.49 .39 surveys $(56.14 \%)$ of participants revealed that they, "never", "rarely", or "sometimes" verbally introduce themselves. Thus, nonverbal identification cues have been reported as a solution to identify others.

\section{Figure 7}

Outcome measures assessed the frequency of self-introduction among participants 


\section{Pre Q7: How often do you introduce yourself to other members of the OR team?}

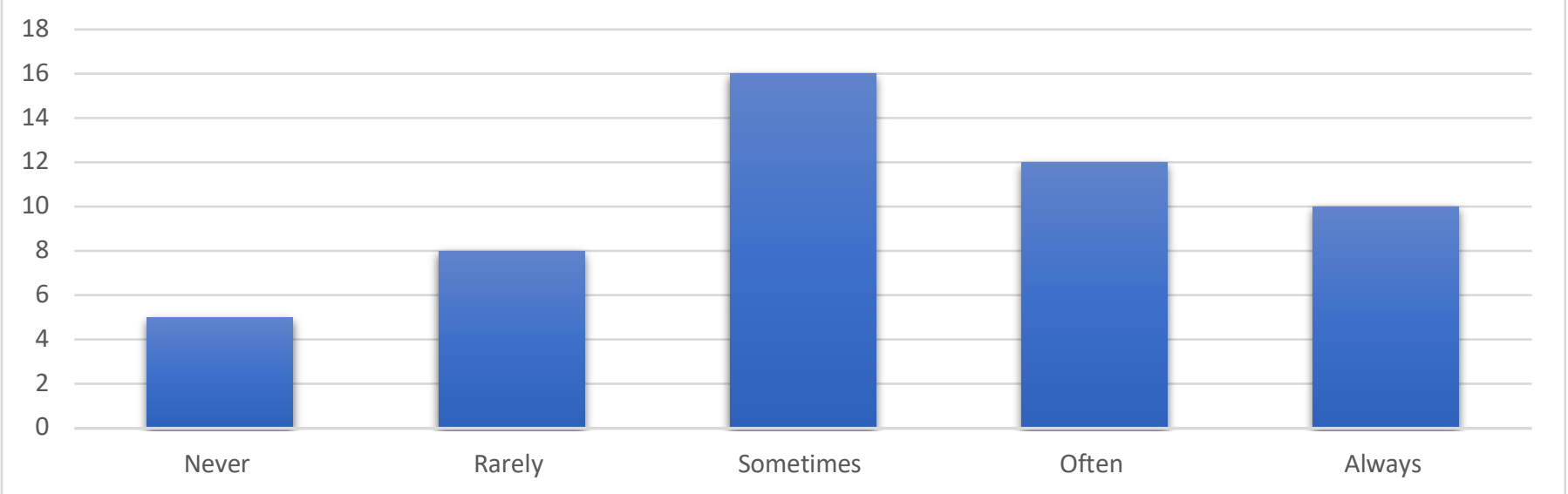

Note. The most common responses among participants involved personal introductory practices.

The majority admitted "sometimes" in relation to self-introduction. Some participants responded that they "rarely" or never introduce themselves in the OR.

A Likert scaled approach to question 8 of the pre-survey asked, "Please indicate your level of agreement with the following statement: Knowing staff members' names and role in the OR improved patient's safety." 3 (6.12\%) responded "strongly disagree," 2 (4.08\%) expressed “somewhat disagree," 4 marked (8.16\%) "neither agree nor disagree," 10 surveys (20.41\%) "somewhat agree," and 30 respondents (61.22\%) "strongly agree." The minimum was 1.0 with the maximum of 5.0, producing a mean of 4.27 , a standard deviation of 1.16 , and a variance of 1.34 for a total of 49 responses. 40 out of 49 (81.63\%) participants "somewhat agree" and "strongly agree" that patients' safety can be impacted by knowing staff members' names and roles in the OR.

\section{Figure 8}

Outcome measures assessed participants' perception on patient safety 


\section{Pre Q8: Please indicate your level of agreement with the following statement: Knowing staff members' names and roles in the OR improves patient safety.}

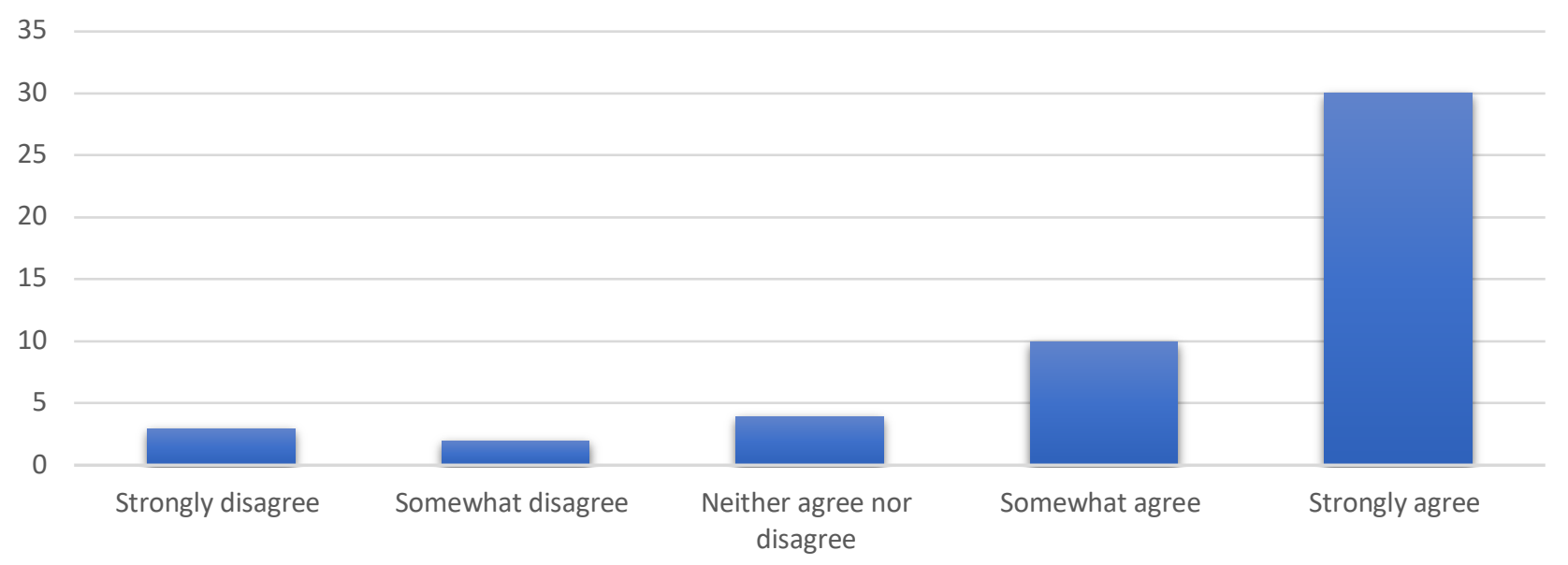

Note. The majority of participants responded knowing staff members' names and roles in the OR improves patient safety.

Another Likert scaled approach of the pre-survey stated, "Please indicate your level of agreement with the following statement: Knowing staff members' names and roles can improve team performance among unfamiliar, de-identified team members dressed in OR PPE.” 3 (6.12\%) responded, "strongly disagree," 2 (4.08\%) responded "somewhat disagree," 2 (4.08\%) marked "neither agree nor disagree," 11 (22.45\%) marked "somewhat agree," and 31(63.27\%) reported "strongly agree." The minimum was 1.0 with the maximum of 5.0, producing a mean of 4.33, a standard deviation of 1.28 and a variance of 0.73 for a total of 49 survey responses.

\section{Figure 9}

Outcome measures assessed participants' perception on team performance 


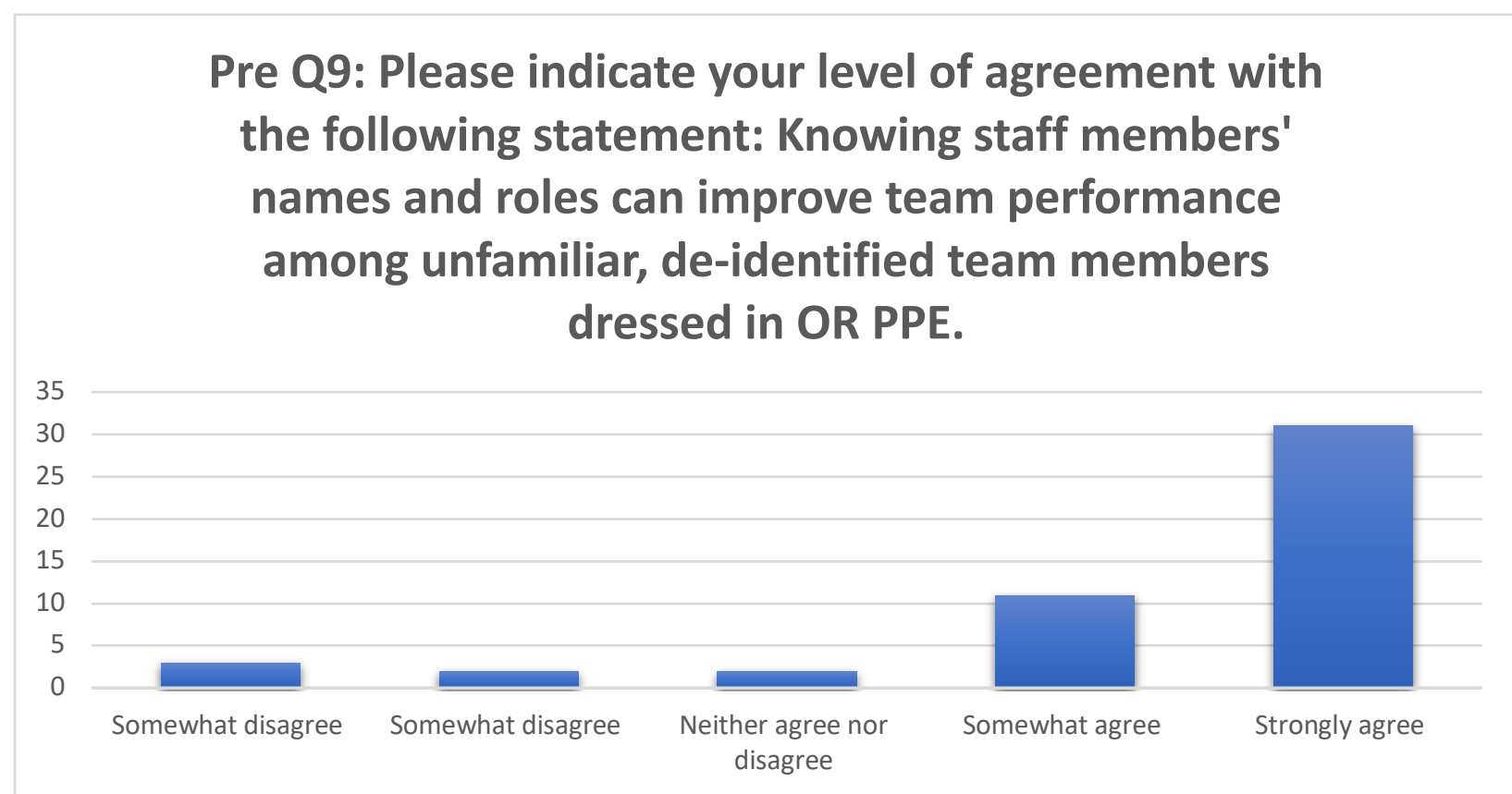

Note. The majority of participants responded knowing staff members' names and roles can improve team performance in the OR.

Post-intervention: A total of 41 paper post-surveys and 3 electronic Qualtrics surveys were obtained (see Appendix G) and 0 were dismissed due to multiple selections on single response only questions. Question 1 aimed to obtain demographic data. The survey responses consisted of 20 nurses (45.45\%), 7 (15.91\%) physicians, 5 (11.36\%) anesthesia providers, 4 $(9.09 \%)$ scrub technicians, $6(13.64 \%)$ student/ trainee responses, $0(0 \%)$ medical sales representatives, and 2 (4.55\%) others which identified themselves as "CST III," and an "X-ray technician."

Figure 10 
Outcome measures of participants' roles

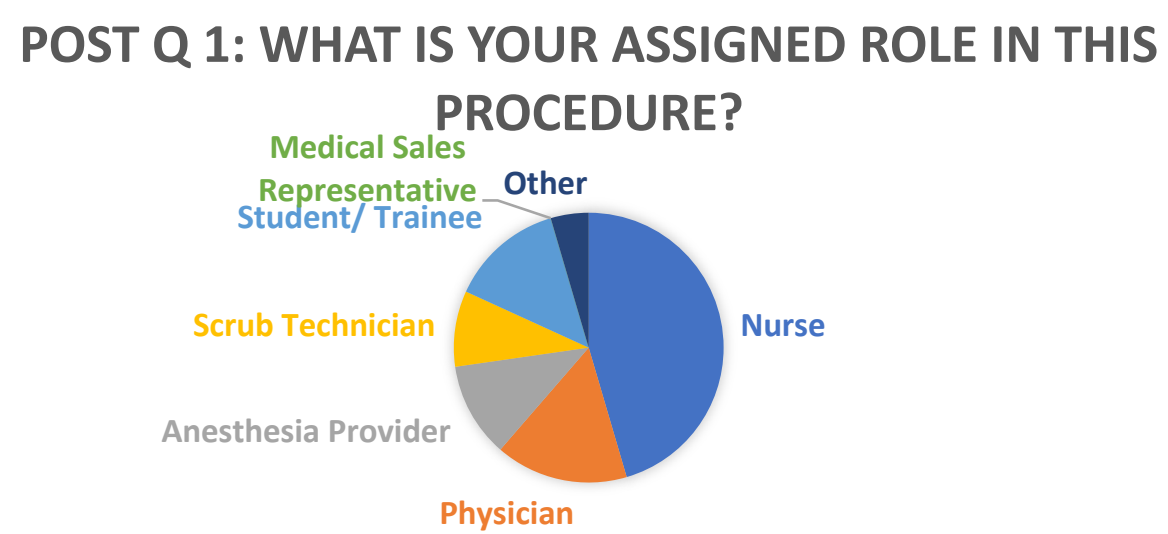

Note. Ordinal data was collected to rank roles.

Urologic OR frequency was assessed by, "How frequently do you work with the staff in today's procedure?" A total of 44 responses were obtained, 2 (4.55\%) marked "never," 16 (36.36\%) marked "monthly," 11 (25\%) worked together "weekly, "15 (34.09\%) reported "daily", resulting in a minimum of 1.0 with the maximum of 4.0 producing a mean of 2.89 , a standard deviation of 0.93 , and a variance of 0.87 .

\section{Figure 11}

Outcome measures assessed participants urological OR exposure

\section{Post Q2: How Frequently fo you work with the staff in today's procedure?}

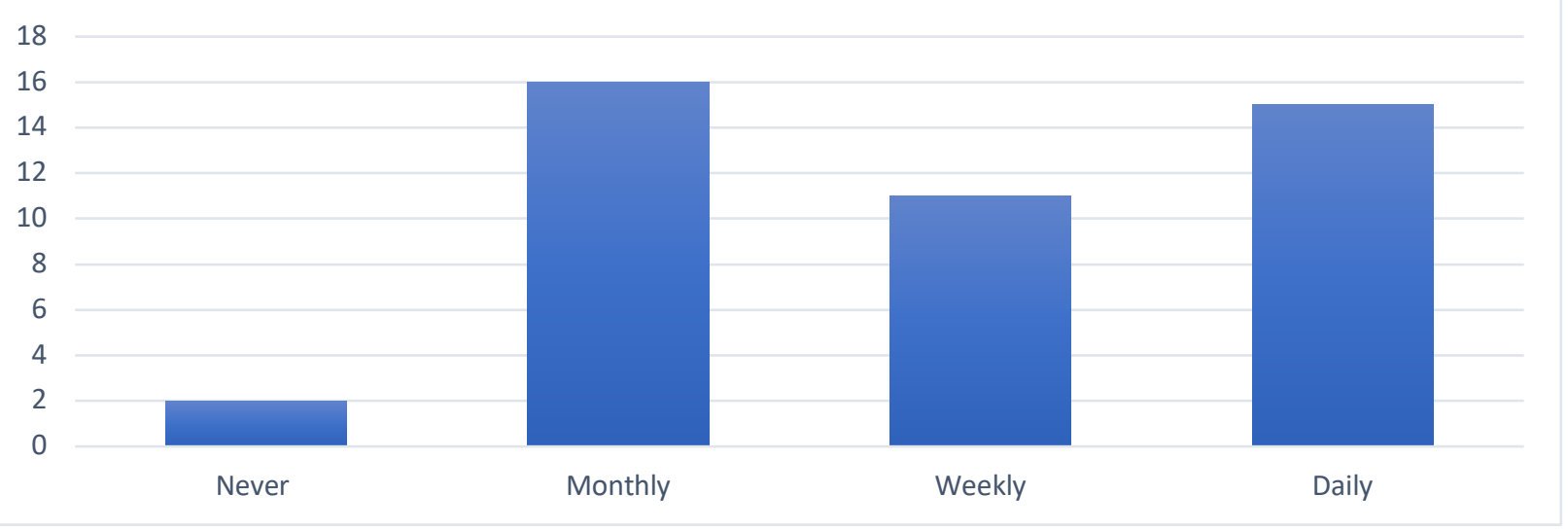


Note. The majority of pre-survey responses reported "daily" which differs from the majority of participants' responses reported "monthly" and "daily" in the post-survey which indicated asymmetry of pre- and post-survey completeness among participants.

To determine the population most identified in the OR, "How many staff members did you know in the procedure?" was questioned. Out of a total of 44 responses, $22(50 \%)$ responded, "I knew every staff member in today's OR including those that relieved breaks." 16 (36.36\%) marked "I knew most of the staff members in the OR," and 6 (13.64\%) indicated "I did not know any of the staff members in the OR." The minimum was 1.0 with the maximum of 3.0 producing a mean of 1.64 , a standard deviation of 0.71 and a variance of 0.50 . In comparison to the 26 participants that reported working in the specialty "weekly" and "monthly", only 22 of the 44 surveys reported that participants knew every member in the procedure, indicating a need for improvement in identification.

\section{Figure 12}

Outcome measures determined the chronic communication breakdown in the OR

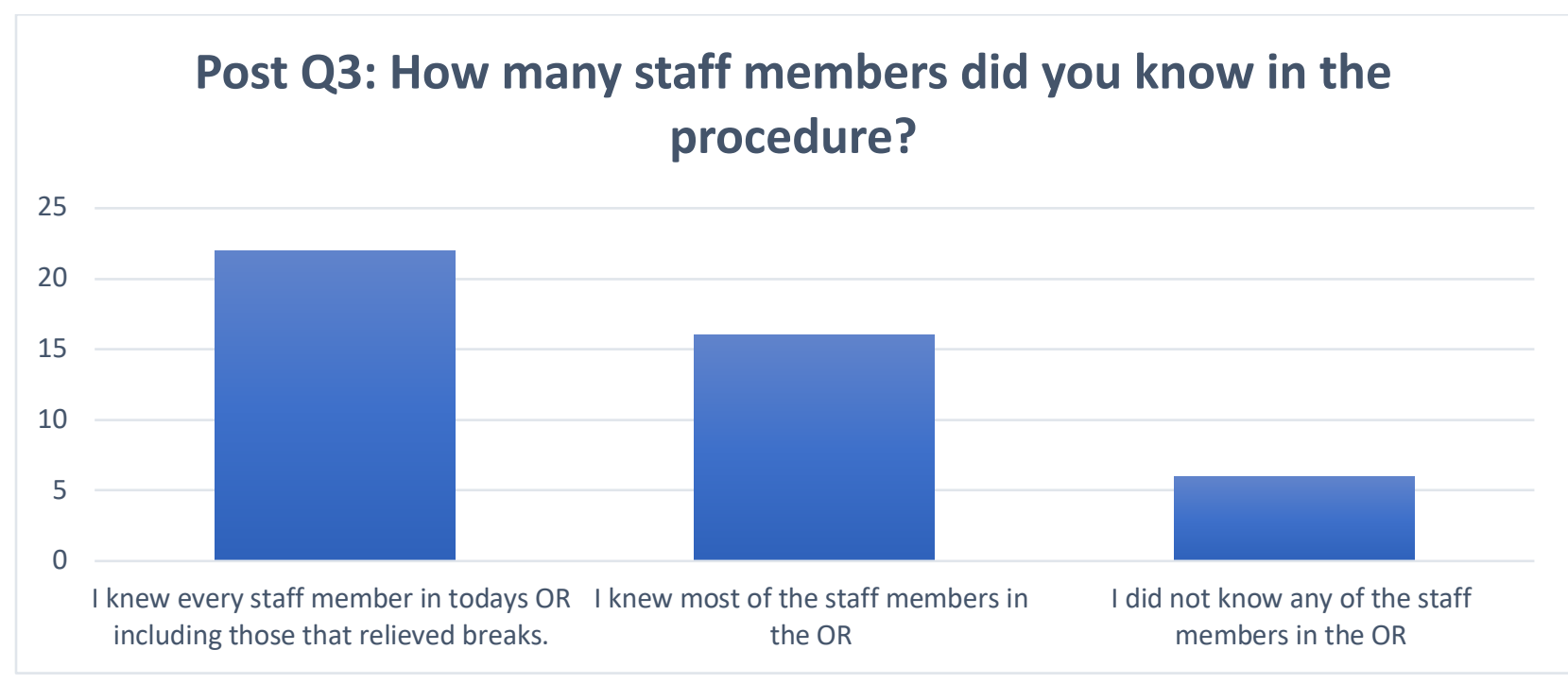

Note. The responses yielded half of participants (22) knew everyone in the OR including those that relieved breaks. However, collaboratively 22 participants responded that they did not 
recognize at least one member in the OR. This finding provided evidence that name and role recognition is an ongoing problem among staff members in the OR.

Expanding on the above question, a multiple select survey design asked participants to, "Identify the team member(s) that you did not know (select multiple if applicable)." A total of 53 responses yielded $13(24.53 \%)$ members did not recognize the "student/trainee," 8 (15.09\%) did not recognize the "scrub technician," along with $8(15.09 \%)$ did not recognize the "anesthesia provider," followed by 7 (13.21\%) did not recognize the "nurse," 7 (13.21\%) did not recognize the "medical sales representative," and 5 (9.43\%) marked "other" with "resident and X Ray technician," "Medical student/D.O. Resident," and 3 "X-ray technicians."5 survey responses (9.43\%) reported that they did not know the "physician" performing the procedure. This DNP project took place at a large academic teaching hospital where students and trainees are currently involved in cases daily. The data revealed that the student aspect of the medical team is the most vulnerable to de-identification in the OR.

\section{Figure 13}

Outcome measures assessed specific groups of unrecognized staff members in the OR

\section{Post Q4: Identify the team member(s) that you did not know (select multiple if applicable)}

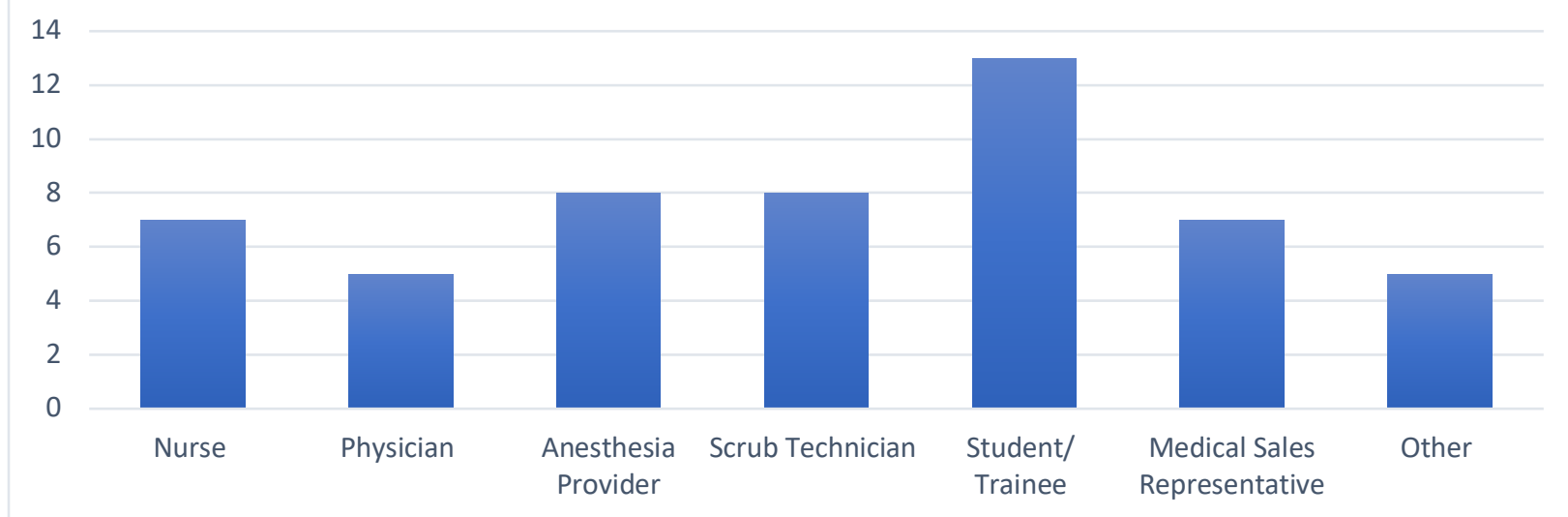


Note. The setting of this DNP project took place in an academic teaching facility where the participants' revealed students/trainees were the least recognized member in the OR.

A Likert scaled design evaluated team communication asked, "To what degree do you feel that a nonverbal identification system displaying name and role on scrub caps enhances communication among OR team members?" A total of 44 responses were received. 2 (4.55 \%) marked "strongly disagree," 4 (9.09\%) "somewhat disagree," 8 (18.18\%) "neither agree nor disagree," 14 (31.82\%) "somewhat agree," and 16 (36.36\%) "strongly agree." The minimum was 1.0 with the maximum of 5.0 , producing a mean of 3.86 , a standard deviation of 1.4 , and a variance of 1.30 . Nearly $70 \%$ (68.18\%) of participants reported, "somewhat" or "strongly agree" to the intervention's effect on the perception of enhanced communication among OR team members. The evidence supported the achievement of the second aim of this QI project.

\section{Figure 14}

Outcome measures assessed the impact of the intervention on team communication

\section{Post Q5: To what degree do you feel that a nonverbal identification system displaying name and role on scrub caps enhances communication among OR team members?}

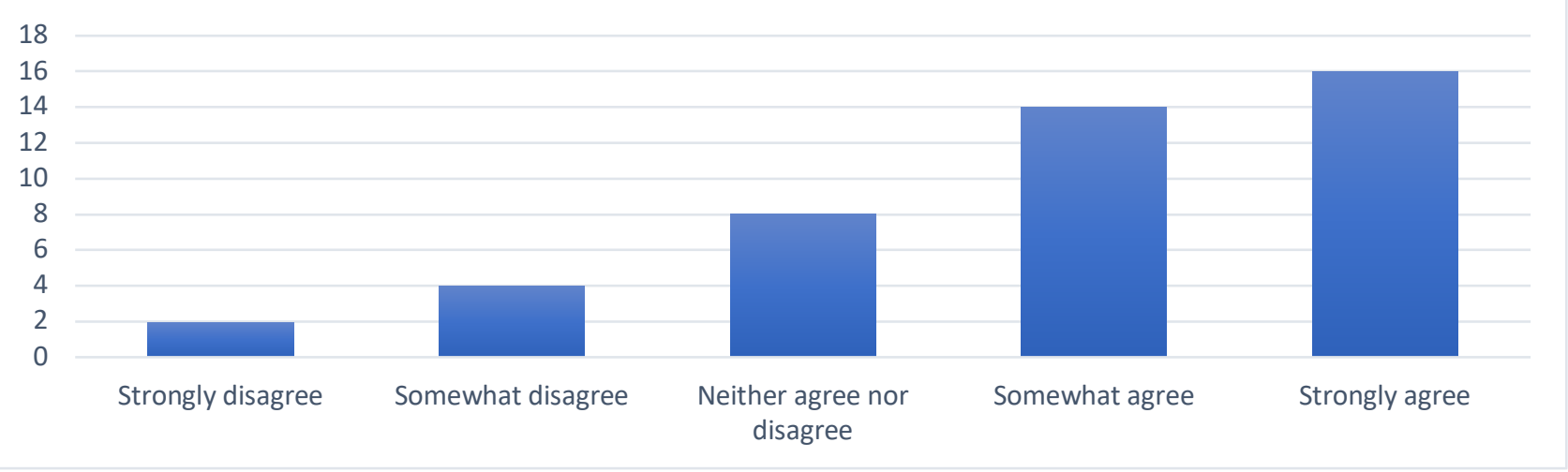

Note. The majority of participants marked a level of agreement to the intervention's impact on enhanced team communication. 
Data was obtained from a Mann-Whitney $U$ Test based off comparative analysis between the pre- and post-surveys. The question, "To what degree do you feel that a nonverbal identification system displaying name and role on scrub caps enhances patient safety in the OR" yielded a total of 44 surveys. 4 (9.09\%) participants responded, "strongly disagree," 2 (4.55\%) “somewhat disagree," 8 (18.18\%) “neither agree nor disagree," 19 (43.18\%) "somewhat agree," and $11(25 \%)$ "strongly agree." The mean for this data set was 3.70 with a standard deviation of 1.16, and a variance of 1.34 . The results of the Mann-Whitney $U$ Test were statistically insignificant ( $\mathrm{p}=0.856)$ when assessing the perception of improved patient safety. However, the outcome of the second specific aim was achieved.

\section{Figure 15}

Outcome measures determined the intervention's impact on the perception of enhanced patient safety

\section{Post Q6: To what degree do you feel that a nonverbal identification system displaying name and role on scrub caps enhances patient safety in the OR?}

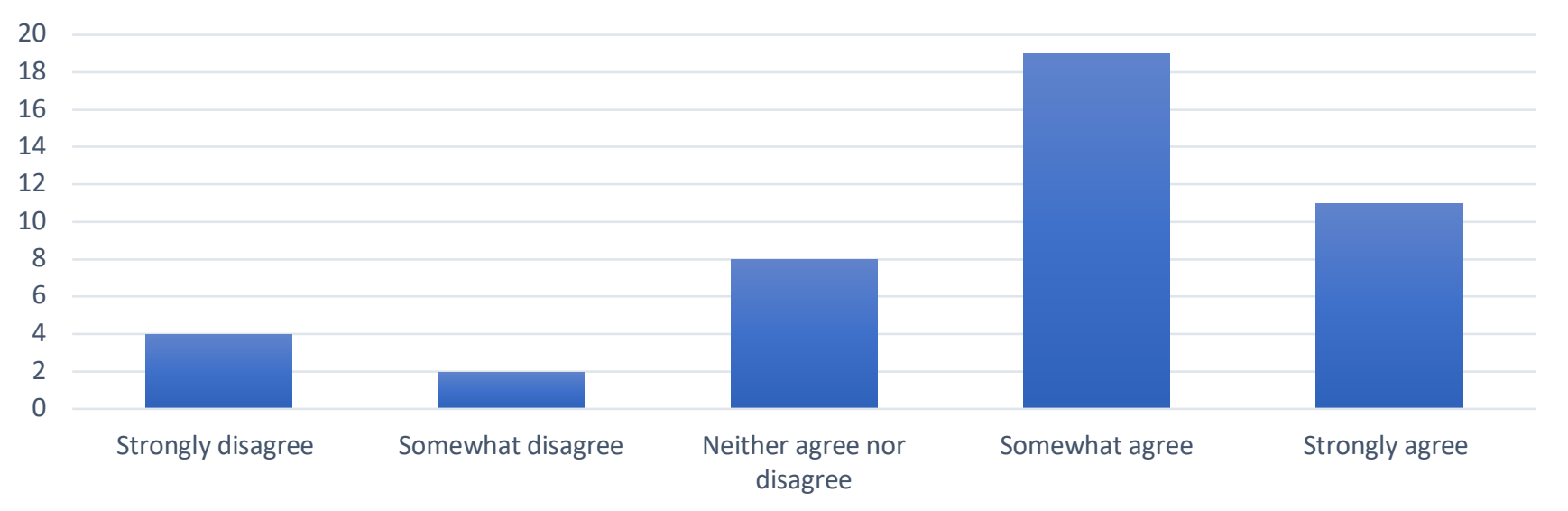

Note. While the results of the Mann-Whitney $U$ Test were statistically insignificant $(\mathrm{p}=0.856)$, the evidence stated that some participants reported the intervention could enhance patient safety. 
A Likert scaled design was used to assess the feasibility of the intervention. This was done by providing questionnaires asking, "How willing would you be to adopt scrub cap identification into your practice if there was a benefit to patient care?" A total of 44 surveys were analyzed. 3 (6.82\%) marked "extremely unwilling," 7 (15.91\%) "somewhat unwilling," 7 (15.91\%) were "neither willing nor unwilling," 11 (25\%) were "somewhat willing," and 16 $(36.36 \%)$ participants were "extremely willing." The minimum was 1.0 with the maximum of 5.0, producing a mean of 3.68, a standard deviation of 1.29, and a variance of 1.67 .27 (61.36\%) participants reported some degree of willingness to adopt this intervention into their everyday practice.

\section{Figure 16}

Outcome measures assessed the feasibility of a self-sustaining project

\section{Post Q7: How willing would you be to adopt a scrub cap identification into your practice if there was a benefit to patient care?}

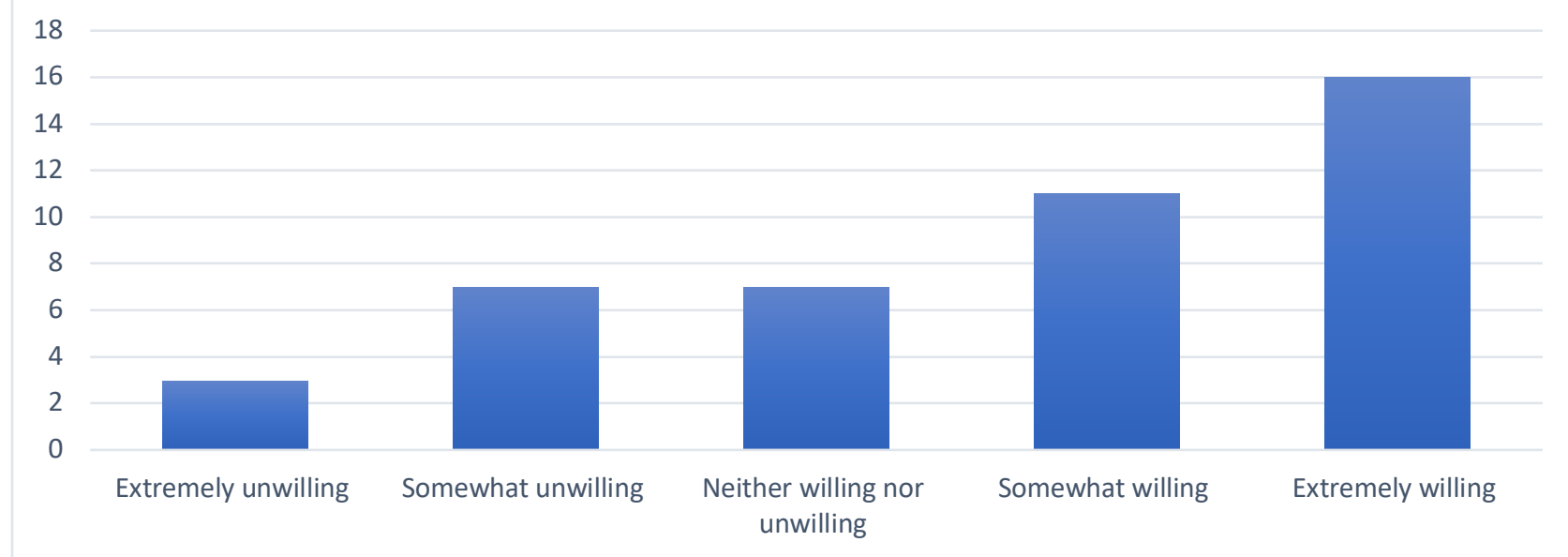

Note. The majority of participants responded some degree of willingness to change their individual practice. 
Question 8 focused on a qualitative response. Participants were asked, "what ways can this intervention be improved in the future?" Similar concepts repeatedly suggested the project would benefit during complex medical cases where multiple disciplines are utilized, such as a general surgery OR. Additional suggestions included embroidered caps to gain long-term participation, self-identification during the time out, and pre-transcribed names for each member to enhance time management.

\section{Contextual Elements Associated with the Intervention}

A standard expectation set by the JC requires all members to wear name badges while in this academic teaching hospital. However, badge wearing can be obscured due to location, smudging, font size, and concealment under sterile gowns in the OR. The intervention of a nonverbal scrub cap identification system was designed to overcome this obstacle. The project design favored the lack of a monotonous OR schedule. This teaching hospital employs a variety of unfamiliar, de-identified staff members that are randomly assigned to each OR and perform with a variety of staff members throughout the shift. The urological specific OR staff members were well educated regarding the project due to their professional, intimate connection with departmental stakeholders and the project leader. Participant's participation may have been influenced from prior personal relationships with the project design team. These connections could have created a Hawthorn effect that had the potential to alter participant's behaviors. The general surgery OR was located on a different floor which was remote from the urological OR suites. Due to the outlying location of the general surgery OR, the project leader struggled to gain participation. 


\section{Observed Associations}

The observed associations pertaining to this project revealed 6 participants who admitted having experienced an adverse event related to the inability of staff members to identify others of the OR team. While the results of the Mann-Whitney $U$ Test on the perception of patient safety were statistically insignificant $(\mathrm{p}=0.856), 30$ out of 44 participants $(68.18 \%)$ agree that a nonverbal scrub cap can enhance communication in the OR.

Collectively, while the perception of patient safety was statistically insignificant, the data revealed that the intervention was reported to enhance the perception of communication among unfamiliar, de-identified staff members. Descriptive analysis revealed that the teaching hospitals' students/ trainees were the most vulnerable to de-identification. Additionally, the physician lacked identification in 5 surveys. The hospital's policy requires verbal identification during the time out, but participants have reported relying on nonverbal communication tools to identify others. Furthermore, more than half of participants (61.36\%) expressed that they were "somewhat willing" or "extremely willing" to adopt a scrub cap identification system into their practice, which aids the feasibility of a self-sustaining project. Utilizing embroidered caps or having pre-transcribed tape prior to the beginning of the case was a common suggestion from participants to gain participation.

\section{Unintended Consequences}

Some unintended consequences arose within the 2-month implementation phase. The first involved the demographics of the general surgery OR as 0 pre- and post-surveys were completed from this room. Assumptions for the lack of participation pertained to the array of disciplines assigned to operate in this location. Thus, participation was difficult to manage. The project leader was able to monitor participation in the urological ORs while assigned to clinical at the 
site. However, the project leader changed clinical rotations during the last three weeks of the project and participation decreased.

The pre- and post-survey design lacked symmetry. The pre- survey consisted of 9 questions which incorporated an additional 2 questions in comparison to the post-surveys. Initial production of the paper surveys were printed front and back. Despite a reminder message for participants to complete the backside questions, the last two questions when the initial survey responses were collected were missing. This observed flaw was quickly altered: thus, reprinted pre-surveys on two stapled pages were provided to prevent mislaid questions.

E- mails were difficult for the project leader to disseminate due to the lack of an innetwork e-mail address, as firewall prevention for out of network messages were flagged due to cyber security. To overcome this hurdle, the chief CRNA e-mailed the anesthesia department and the project leader notified staff at a monthly virtual team meeting. The project leader placed an informative poster on the bulletin board in the OR hallway to notify those absent from the meeting. The lack of participation can relate to the inability to notify every potential participant. The development of professional relationships proved cumbersome between the participants and the project leader due to COVID-19 restrictions which required social distancing. COVID-19 restrictions enforced electronic meetings which hindered opportunities to form a rapport with members of the OR team which had the potential to be favorable for participation.

\section{Missing Data}

Throughout the implementation phase the project leader noticed unforeseen consequences. Data analysis revealed an increase in pre-survey responses in comparison to postsurvey submissions. This asymmetrical data analysis favored the increased amount of pre-survey responses may be explained due to time management favoring the beginning of the procedure as 
opposed to the hectic turnover in-between patients. All post-survey questions were answered but 1 responder omitted question 4 of the pre-survey asking the perception of identification difficulty while dressed in PPE. 50 out of 51 responses were obtained for question 5 of the pre-survey asking, "Do you think that being able to distinguish names and roles help to improve patient's safety?" 48 out of 51 responses were obtained for question 8 of the pre-survey asking, "Please indicate your level of agreement with the following statement: Knowing staff members names and roles in the OR improves patient safety." 2 responses were omitted on question 9 of the presurvey which stated, "Please indicate your level of agreement with the following statement: Knowing staff members names and roles can improve team members' performance among unfamiliar, de-identified team members dressed in OR PPE." In accordance with the statistician's recommendation, 11 surveys were discarded due to multiple responses on single select only questions. Discarding survey responses were recommended to ensure non bias data was collected between the electronic and paper format survey designs. Due to the logistics of the project, the current pandemic considerations, and the need to obtain an adequate sample size, expert opinion was considered. Thus, pre- and post-surveys were not able to be paired for feasibility of the project. A statistical comparative analysis was unable to be performed to examine enhanced team communication between the pre- and post- surveys because the surveys lacked comparable questions, which was noted as a flaw in the tool.

\section{Discussion}

\section{Summary}

\section{Key Findings}

The specific aims of this DNP project explored the effect of a name and role identification intervention on staff's perceptions of patient safety. Additionally, the project aimed 
to determine the effect of a name and role identification intervention on team performance among unfamiliar, de-identified team members dressed in OR PPE. Key findings for this DNP project involved an unexpected finding of 6 reported adverse patient events related to the inability of staff identification. This quality improvement project suggested enhanced team performance as evidence by more than half of participants (68.18\%) marked, "somewhat agree" or "strongly agree" to the intervention's impact on communication. A Mann-Whitney UTest produced statistically insignificant data $(\mathrm{p}=0.856)$ pertaining to the staff's perception on the intervention's enhancement on patient's safety. An unexpected finding included more than half of participants (61.36\%) expressed that they were "somewhat willing" or "extremely willing" to adopt this QI project into their practice if there was a benefit to patient care.

Due to rapidly changing COVID-19 restrictions, posing challenges in an already assiduous workplace, participation lacked, and further research on this topic is imperative to monitor the success of the intervention.

\section{Project Strengths}

As part of a strengths, weaknesses, opportunities, and threats (S.W.O.T) analysis, strengths for this project were evaluated. The first strength incorporates improving recognition of unfamiliar, de-identified staff members that pose a threat to communication. Such instances include OR settings where staff members must wear head to toe PPE and uniformly dress in one scrub color regardless of their role. Additionally, the intervention ensured proper names were utilized when delegating tasks. Patient specific names utilized for delegation were more likely to cause a clear and informative direction to achieve an active response (Jung et al., 2018). This QI intervention can reduce financial loss due to miscommunication among staff members and drives the feasibility for the intervention due to the low-cost analysis referenced in a previous section. 


\section{Interpretation}

\section{Association between the Intervention and the Outcomes}

The association between the intervention and the outcomes suggest an improvement in the perception of staff communication among unfamiliar, de-identified staff members. Statistical analysis of the Mann-Whitney $U$ Test revealed insignificant results $(\mathrm{p}=0.856)$ related to the perception of enhanced patient safety. Teaching facilities are currently accustomed to fostering students as an active member of the OR. The results yielded: students/trainees were the most vulnerable population to misidentification. The physicians were the most recognized in the OR setting. However, an unexpected finding yielded $9.43 \%$ for a total of 5 survey responses indicated that a member in the OR did not know the physician whom they were working with. The hospital policy encourages all members, specifically the physician, to ensure every member of the OR team verbally self-identify during the time-out. A flaw in identification was noticed as 6 participants reported that they did not know any of the staff members working in the OR. Unforeseen evidence displayed 6 reports of an adverse event related to the inability of providers to identify each other. Further research on this project is required, as 6 respondents expressed the lack of knowing every member in the OR, which appears to be a chronic finding in academic literature and within this DNP project.

\section{Comparison of Results with other Publications}

A comparison of the results with other publications was initially difficult to accomplish during the proposal phase of this DNP project due the lack of literature on a nonverbal scrub cap identification system. A key opportunity allowed for research to determine the effectiveness of Dr. Hackett's novel scrub cap identification system regarding staff members' communication and perception on patient safety. During the post implementation phase, the project leader 
discovered a published study produced at the cessation of the intervention in 2020. Douglas et al. (2020) disclosed statistically significant evidence of enhanced identification of staff members who used a nonverbal scrub cap identification strategy $(\mathrm{p}<0.001)$. The study produced statistically insignificant results $(p=0.058)$. The findings justified the null hypothesis between wearing a scrub cap identification versus the absence of using the intervention. The methods of this study design paralleled the DNP projects hypothesized improvement in communication assessed by a Likert scaled study design. Additionally, the data presented an opportunity for future interventions. Descriptive data presented to the academic teaching hospital is crucial for administration to understand and improve verbal communication breakdowns, understand vulnerable populations, and acknowledge the lack of visibility of JC required badges under sterile PPE in an OR environment.

\section{Impact of the Project on People and Systems}

This DNP project focused on the intervention's effect on participant's perception of patient safety and the enhancement of communication among unfamiliar, de-identified, and uniformed OR staff members. Licensed personnel have a duty to protect their patients. 46 out of 50 participants (92\%) agreed that being able to distinguish names and roles would help improve patient's safety. Patient care is at the core of all healthcare institutions. To be a successful organization, adverse events must be minimized as financial burdens can hinder a return on investment. A review of the 2019 Board of Medicine in West Virginia malpractice insurance claims totaled 2 counts of judgement in legal action and 92 settlement suits accounting for $\$ 41,509,500$. Communication disintegrations often lead to malpractice litigations. Communication breakdowns were often higher in cases involving provider-to- provider 
communication errors than compared to provider to patient communication mistakes (Sullivan Group, 2020).

\section{Rationale for Varying Outcomes}

An anticipated outcome for the project determined the impact of a nonverbal scrub cap identification system on the perception of patient safety among unfamiliar, de-identified OR team members dressed in PPE. Analysis from the Mann-Whitney $U$ Test revealed this outcome was not achieved because the $p$ value was $>0.05(p=0.856)$. Data was potentially skewed by the need to eliminate 11 paper surveys.

The outcome pertaining to communication effecting team performance suggested enhanced perception of communication when utilizing a nonverbal scrub cap identification system among unfamiliar, de-identified OR staff members. The urological-hired ORs suggested that the project would benefit from an interdisciplinary OR setting. The project leader collected the majority of surveys from the same day urological ORs compared to the general surgery ORs where urologic procedures sparsely occurred. Break relief can often be overlooked, thus having an impact on the outcomes as he or she joins the team during an obscure time. These individuals often miss the timeout and lack a specified moment to introduce themselves during an ongoing surgery. The majority of data was collected from familiar staff members which had the potential to skew data when compared to the nonspecific general surgery rooms.

\section{Cost Savings}

Anticipated expenses were negligible and included the expense of surgical tape, disposable surgical caps, and a Sharpie marker that were provided by the hospital's central supply chain. Surveys were initially printed on double sided pages. The project leader reprinted 
the surveys on separate pages to minimize the missing data that was noticed during the first week of the intervention's implementation phase.

\section{Limitations}

\section{Limits to Generalizability}

The generalizability of this project is broadly applicable to many different types of people or situations. However, the project utilized a large healthcare facility where the majority of staff members were unfamiliar with one another. This project may not be feasible in a facility that has consistent OR staff who collaborate daily. Familiar, identified staff members have the potential to skew the necessity of the intervention. A smaller facility employing staff members that are familiar with one another may not possess a need for this intervention.

\section{Limits to Internal Validity}

Limits to internal validity may have impacted this DNP project. The project leader developed relationships with the urological OR RNs throughout personal clinical obligations at the hospital. The consultant, Dr. Crigger, was a practicing physician and key stakeholder in the project was employed in the department which may have impacted participation through passive coercion. Peer anesthesia students were reminded to participate in the project. Surveys were not paired and an increased number of pre-surveys in comparison to post-surveys had the potential to impact data. Survey completion depended on RNs encouragement at the cessation of the case. Additionally, participation lacked in the general surgery OR when urologic cases were randomly assigned, a common setting for unfamiliar, de-identified staff members. Unfamiliarity with the project impacted participation including the logistics of the general surgery OR being on a separate floor. 


\section{Minimizing Limitations}

The project leader placed a high importance on minimizing limitations when designing this DNP project. The project leader adapted when presented with unforeseen scenarios. During the planning phase, Qualtrics Surveys were created on an online platform and printed to minimize technological accessibility barriers. During the first week of the implementation phase, paper copies were reprinted on multiple pages due to the assumption that participants overlooked the back side of the paper despite instructions to complete the reverse side.

\section{Conclusion}

\section{Usefulness of the Intervention}

Effective communication is imperative within a healthcare system. This local trauma hospital employs hundreds of staff members from surrounding areas, which aids to an increased incidence of unfamiliar members collaborating to perform patient care. Unfamiliar, de-identified OR staff members can be a threat to communication. The COVID-19 virus is currently an ongoing pandemic requiring staff members to wear head to toe PPE. Consequently, facial recognition is impacted by masking requirements which can negatively impact identification of others and impede the intended message (Douglas et al. 2020). The hospital policy states that individuals should identify oneself during the time out but break relief may not be present during this event. The use of a nonverbal communication strategy can serve as a reminder for those who experience difficulty with verbal recall, hearing impairments, or staff members that have entered the case during an obscure timeframe. This DNP project aimed to serve as a pilot project for future research. Future projects can replicate the exact implementation method and project design. Furthermore, the improvement of the survey design tool to incorporate comparable pre- 
and post-survey questions can better evaluate the statistical significance of a nonverbal scrub cap communication strategy.

\section{Sustainability}

The sustainability of this DNP project depended on the participant's perception of the project's importance. The project leader promoted the project daily by wearing a personal embroidered scrub cap. The concept has been introduced into the hospital system with one CRNA adopting the intervention into their daily routine. The OR staff will have the option to continue and espouse the change into practice. More than half of participants $(61.36 \%)$ expressed "somewhat willing" or "extremely willing" to adopt the intervention into practice which aids to the feasibility of a self-sustaining project.

\section{Recommendations}

Future recommendations for this quality improvement project would include the use of congruent pre- and post-surveys to improve the reliability and validity of the tool. Additionally, in person communication with OR staff may increase participation and aid in data collection. Lastly, pre transcribed tape incorporating names and roles upon participant arrival was a common suggestion noted in the post-survey responses. 


\section{References}

Bodor, R., Nguyen, B. J., Broder, K. (2017). We are going to name names and call you out! Improving the team in the academic operating room environment. Ann Plastic Surgery, 78(5) S222- S224. doe: 10.1097/SAP.0000000000001092

Bonne, W., Smith, K. V. (2018). Proposal writing for clinical nursing and DNP projects. (2 ${ }^{\text {nd }}$ ed.) Springer Publishing Company.

Caprice, C., Greenberg, M.D., Reengage, S. E., Stoddert, D. M., Stuart, R. L., Selwyn, O. R., Zenner, M. J., Atul, A. G. (2007). Patterns of communication breakdowns resulting in injury to surgical patients. Journal of the American College of Surgeons, 204(4), 533540. https://doi.org/10.1016/j.jamcollsurg.2007.01.010

Centers of Disease Control and Prevention. (2020). Logic model.

https://www.cdc.gov/eval/logicmodels/index.htm\#: :text=A\%20logic $\% 20$ model $\% 20 \mathrm{is} \% 20 \mathrm{a}$, acti vities $\% 20$ and $\% 20$ its $\% 20$ intended $\% 20$ effects

Chism, L. A. (2015). The essentials of the doctor of nursing practice: A philosophical perspective. ( $2^{\text {nd }}$ ed.). Jones \& Bartlett Learning. http://samples.jbpub.com/9781284041347/9781284041347_CH03 pass02.pdf

Dingley, C., Daugherty, K., Derig, M. K., Parsing, R. (2008). Improving patient safety through provider communication strategy enhancements. In Henriksen, K., Battles, J.B., Keyes,

M.A., \& Grady, M.L. (Eds.), Advances in Patient Safety: New Directions and Alternative

Approaches, (Vol. 3). Agency for Healthcare Research and Quality. https:/www.ncbi.nlm.nih.gov/books/NBK43663/

Douglas, N., Demetri, S., Conlang, K., Salmon, P., Chee, B., Sullivan., Helena, D., Oscan, J., Symons, G., Marine, C. (2020). Surgical caps displaying team members' names and roles 
improve effective communication in the operating room: a pilot study Journal of patient safety in surgery. 15(1) 27. doe: 10.1186/s13037-021-00301-w.

Healthy People 2020. (2020). Global health. Office of Disease Prevention and Health Promotion. https://www.healthypeople.gov/2020/topics-objectives/topic/global-health

Hogue, M. H., Hellmann, K. P., Callaghan, J. J. (2017). Wearing ID badges in the operating room environment: Is reconsidering warranted? Journal of Arthroplasty, 32(7), 22312233. doe: $10.1016 /$ j.arth.2017.01.046

Jung, Y. S., Paik, H., Min, S. H., Choo, M. Sea, J. H., Bahk, J. H. (2016). Calling the patient's own name facilitates recovery from general anesthesia: A randomized double-blind trial. Anesthesia, 72(2), 197-203. https://doi.org/10.1111/anae.13688

Kern, C. (2020) Healthcare miscommunication costs 2,000 lives and 1.7 billion. Health IT Outcomes https://www.healthitoutcomes.com/doc/healthcare-miscommunication-costslivesandbillion0001\#: :text=Poor $\% 20$ communications $\% 20$ cost $\% 20$ the $\% 20$ U.S.,filed $\% 20$ betwee $\underline{\mathrm{n} \% 202009 \% 20 \text { and } \% 202013}$

Lapakko, D. (1997). Three cheers for language. A closer examination of a widely cited study of nonverbal communication. Communication Education, 46(1), 63. https://doi-org. wvu.idm.oclc.org/10.1080/03634529709379073

Petiprin, A. (2016). Lewin's change theory. Nursing Theory. https://nursing-theory.org/theories-and-models/lewin-change-theory.php

Rosen, D. A., Criser, A. L., Petrone, A. B., Jackson, E., \& Bowers, J. (2019). Utilization of a role-based head covering system to decrease misidentification in the operating room. Journal of Patient Safety, 15(4), e90-93. https://doi.org/10.1097/pts.0000000000000608

Rosswurm, M. A., Larrabee, J.H. (1999) A model for change to evidence-based practice. Journal 
of Nursing Scholarship, 31(4), 317-322. https://doi.org/10.1111/j.1547-5069.1999.tb00510.x

Shirey, M.R. (2013). Lewin's theory of planned change as a strategic resource. Journal of Nursing Administration, 43(2), 69-72. https://doi.org/10.1097/NNA.0b013e31827f20a9

Sullivan. (2020). Strategies to improve provider-patient communication. https://blog.thesullivangroup.com/strategies-to-improve-provider-patient-communication

Sullivan, G. M., \& Artino, A. R., Jr. (2013). Analyzing and interpreting data from likert-type scales. Journal of Graduate Medical Education,5(4), 541-542. https://doi.org/10.4300/JGME-5-4-18

Tija, J., Mazor, K, M., Field, T., Meterko, V., Spenard, A., Guritz, J. H. (2009). Nurse- physician communication in the long-term care setting: perceive barriers and impact on patient safety. Journal of Patient Safety 5(3) 145-152. doi: 10.1097/PTS.0b013e3181b53f9b. PMID: 19927047; PMCID: PMC2757754.

West Virginia University [WVU] Medicine. (2020). J. W. Ruby memorial hospital: Urology. https://wvumedicine.org/ruby-memorial-hospital/services/wvu-specialty-c linics/urology/\#: :text=WVU\%20Medicine\%20urologists\%20perform\%20more, assisted $\% 20$ surgical $\% 20$ procedures $\% 20$ each $\% 20$ year.

West Virginia University [WVU] Medicine. (2020). Mission and vision. https://wvumedicine.org/about/leadership-and-more/mission-and-v ision/\#: :text=To\%20improve $\% 20$ the $\% 20$ health $\% 20$ of,care $\% 2 \mathrm{C} \% 20$ research $\% 2 \mathrm{C} \% 20$ and $\% 20$ education. 
Appendix A

Pre- Intervention Survey

\title{
Figure 1
}

\author{
Scrub Hat Identification Project \\ Preintervention Survey \\ Directions: Please mark the circle with an " $\mathrm{X}$ " or check mark next to your answer on both sides.
}

Q1: What is your assigned role in this procedure?

- Nurse

- Physician

- Anesthesia Provider

- Scrub Technician

- Student/Trainee

- Medical Sales Representative

- Other: Please Specify

Q2: How frequently do you work in this urology specialty?

$$
\begin{array}{ll}
\circ & \text { Rarely } \\
\circ & \text { Monthly } \\
\circ & \text { Weekly } \\
\circ & \text { Daily }
\end{array}
$$

Q3: Has a patient in your care ever had an adverse event related to the inability of providers to identify each other?

$\begin{array}{ll}\circ & \text { Yes } \\ \circ & \text { No }\end{array}$

Q4: How difficult is it to identify staff members roles while fully donned in protective equipment (PPE)?

- I find it easy to identify every member assigned in the $O R$

- I can identify almost every member in the OR, but I do not know everyone in the case

- I struggle to identify others in the $O R$

Q5: Do you think that being able to distinguish names and roles would help improve patient's safety? $\circ$ Yes

$\circ$ No

Q6: What is your most common practice to identify others in the OR team?

- I know everyone's role and name in the OR

- I ask staff members their name and role for every case

- I look for nonverbal cues such as identification badges

- I ask others if I don't know an unfamiliar team member

- I do not seek to learn other people's name and roles

Q7: How often do you introduce yourself to other members of the OR team?

- Never

- Rarely

- Sometimes

- Often

$\circ$ Always

Note. First page of pre-survey questionnaire. 
Appendix A

\title{
Pre-Intervention Survey
}

\section{Figure 1}

\author{
Scrub Hat Identification Project \\ Preintervention Survey \\ Directions: Please mark the circle with an "X" or check mark next to your answer on both sides.
}

Q8: Please indicate the level of agreement with the following statement: Knowing staff members names and role in the OR improves patient's safety.

- Strongly disagree

- Somewhat disagree

- Neither agree nor disagree

- Somewhat agree

- Strongly agree

Q9: Please indicate your level of agreement with the following statement: Knowing staff members names and roles can improve team performance among unfamiliar, de-identified team members dressed in OR PPE.

- Strongly disagree

- Somewhat disagree

- Neither agree nor disagree

- Somewhat agree

- Strongly agree

Note. Second page of pre-survey questionnaire. 


\title{
Appendix B
}

\section{Post-Intervention Survey}

\author{
Scrub Hat Identification Project \\ Post Intervention Survey \\ Directions: Please mark the circle with an "X" or check mark next to your answer.
}

Q1: What is your assigned role in this procedure?

- Nurse

- Physician

- Anesthesia Provider

- Scrub Technician

- Student' Trainee

- Medical Sales Representative

- Other: Please Specify

Q2: How frequently do you work with the staff in today's procedure?

$$
\begin{array}{ll}
- \text { Never } \\
\text { Monthly } \\
\text { Weekly } \\
\text { Daily }
\end{array}
$$

Q3: How many staff members did you know in the procedure?

- I knew every staff member in today's OR, including those that relieved breaks

- I knew most of the staff members in the OR

- I did not know any of the staff members in the OR

Q4: Identify those whom you did not know their name AND role (seleet multiple if applicable)
- Nurse
- Physician
- Anesthesia Provider
- Scrub Technician
- Student' Trainee
- Medical Sales Representative
- Other: Please Specify

Q5: To what degree do you feel that a nonverbal identification system displaying name and role on scrub caps enhances communication among OR team members?

- Strongly disagree

- Somewhat disagree

- Neither agree nor disagree

- Somewhat agree

- Strongly agree

Q6: To what degree do you feel that a nonverbal identification system displaying name and role on scrub eaps enhances patient safety in the OR?
- Strongly disagree
- Somewhat disagree
- Neither agree nor disagree
- Somewhat agree
- Strongly agree

Q7: How willing would you be to adopt scrub cap identification into your practice if there was a benefit to patient care?
- Extremely unwilling
- Somewhat unwilling
- Neither willing nor unwilling
- Somewhat willing
- Extremely willing

Q8: What ways can this intervention be improved in the future?

Note. Postintervention-survey questionnaire 


\section{Appendix C}

\section{Budget Plan}

\begin{tabular}{|c|c|c|}
\hline Budget Categories & Personal Funds & $\begin{array}{l}\text { Organizational } \\
\text { Contributions }\end{array}$ \\
\hline ADMINISTRATIVE COSTS & $\$ 0$ & $\$ 0$ \\
\hline \multicolumn{3}{|c|}{$\begin{array}{l}\text { Administrative Justification: No financial commitment necessary for delivery of in-service. Only } \\
\text { a small (30 min hourly salary) for educational presentation }\end{array}$} \\
\hline MARKETING & $\$ 0$ & $\$ 0$ \\
\hline \multicolumn{3}{|l|}{ Marketing Justification: n/a } \\
\hline $\begin{array}{l}\text { EDUCATIONAL MATERIALS/ } \\
\text { INCENTIVES }\end{array}$ & $\$ 0$ & $\$ 0$ \\
\hline \multicolumn{3}{|c|}{$\begin{array}{l}\text { Educational Materials/Incentives Justification: Materials can be distributed electronically at no } \\
\text { cost. }\end{array}$} \\
\hline $\begin{array}{l}\text { HOSPITALITY (food, room rentals, } \\
\text { etc.) }\end{array}$ & $\$ 0$ & $\$ 0$ \\
\hline \multicolumn{3}{|l|}{ Hospitality Justification: $\mathrm{n} / \mathrm{a}$} \\
\hline $\begin{array}{l}\text { PROJECT SUPPLIES (office } \\
\text { supplies, postage, printing, etc.) }\end{array}$ & $\$ 15$ & $\$ 6.39$ \\
\hline \multicolumn{3}{|l|}{ Project Supplies Justification: $\mathrm{n} / \mathrm{a}$} \\
\hline TRAVEL EXPENSES & $\$ 0$ & $\$ 0$ \\
\hline \multicolumn{3}{|l|}{ Travel Expenses Justification: n/a } \\
\hline OTHER & $\begin{array}{l}\text { Participants already } \\
\text { approved hourly wage } \\
\text { due to implementation } \\
\text { will occur throughout } \\
\text { business hours }\end{array}$ & $\begin{array}{l}\text { Hourly wages already } \\
\text { approved by Nicole } \\
\text { Whitlock }\end{array}$ \\
\hline
\end{tabular}

Note. Budget plan for this QI project. 


\section{Appendix D}

\section{Project Timeline}

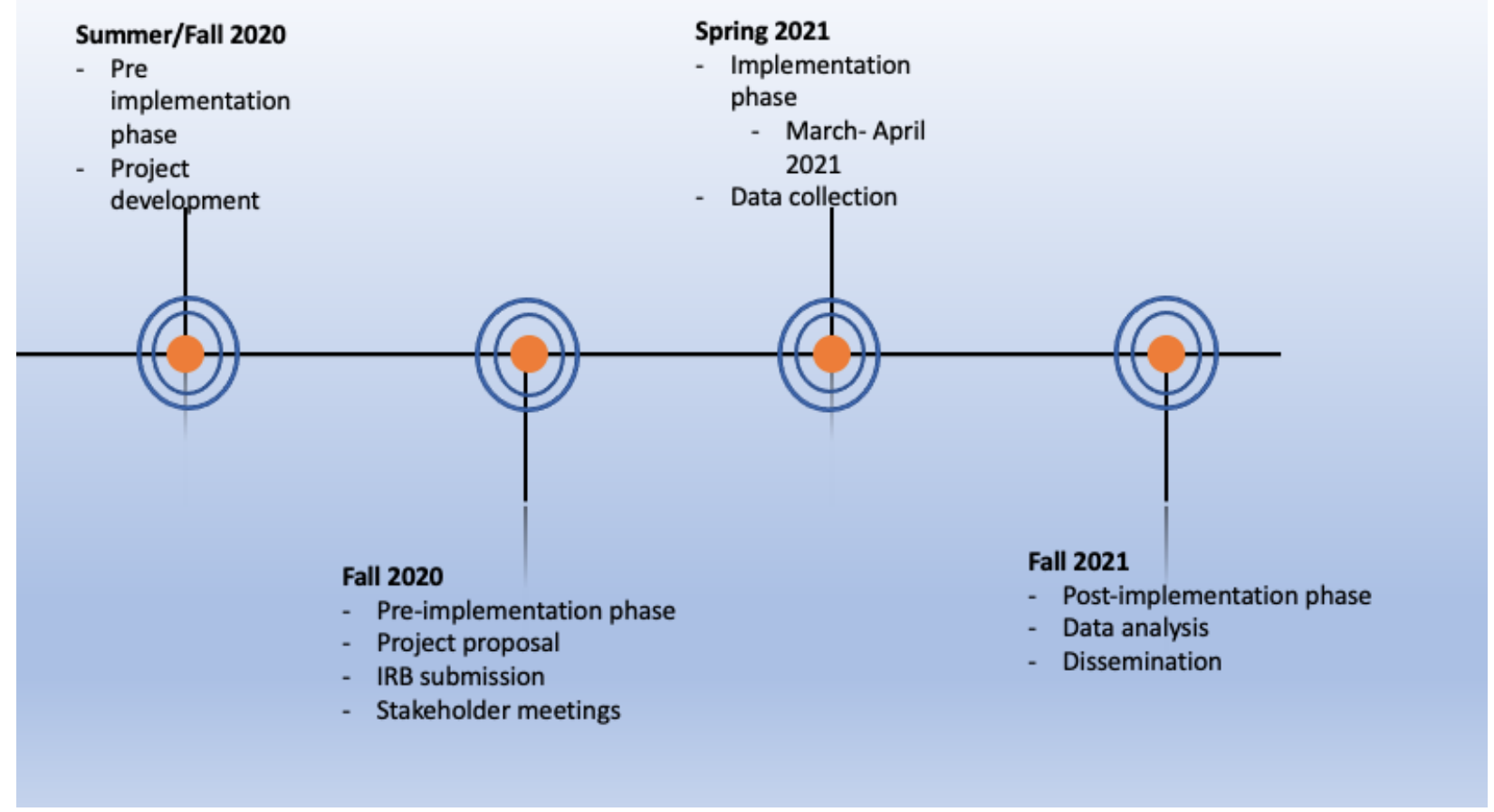

Note. DNP project timeline 


\section{Appendix E}

\section{Mann- Whitney $U$ Test Results}

\section{Figure 1}

\section{NPar Tests}

\section{Mann-Whitney Test}

\section{Test Statistics ${ }^{\mathrm{a}}$}

\begin{tabular}{|c|c|c|c|c|}
\hline & PRE & $\mathrm{N}$ & Mean Rank & $\begin{array}{l}\text { Sum of } \\
\text { Ranks }\end{array}$ \\
\hline \multirow[t]{3}{*}{ POST } & 1.00 & 39 & 22.12 & 862.50 \\
\hline & 2.00 & 4 & 20.88 & 83.50 \\
\hline & Total & 43 & & \\
\hline
\end{tabular}

\begin{tabular}{lr} 
& \multicolumn{1}{c}{ POST } \\
\hline Mann-Whitney U & 73.500 \\
\hline Wilcoxon W & 83.500 \\
\hline$Z$ & -.199 \\
\hline Asymp. Sig. (2-tailed) & .842 \\
\hline $\begin{array}{l}\text { Exact Sig. [2(1-tailed } \\
\text { Sig.)] }\end{array}$ & $.856^{\mathrm{b}}$ \\
\hline
\end{tabular}

a. Grouping Variable: PRE

b. Not corrected for ties.

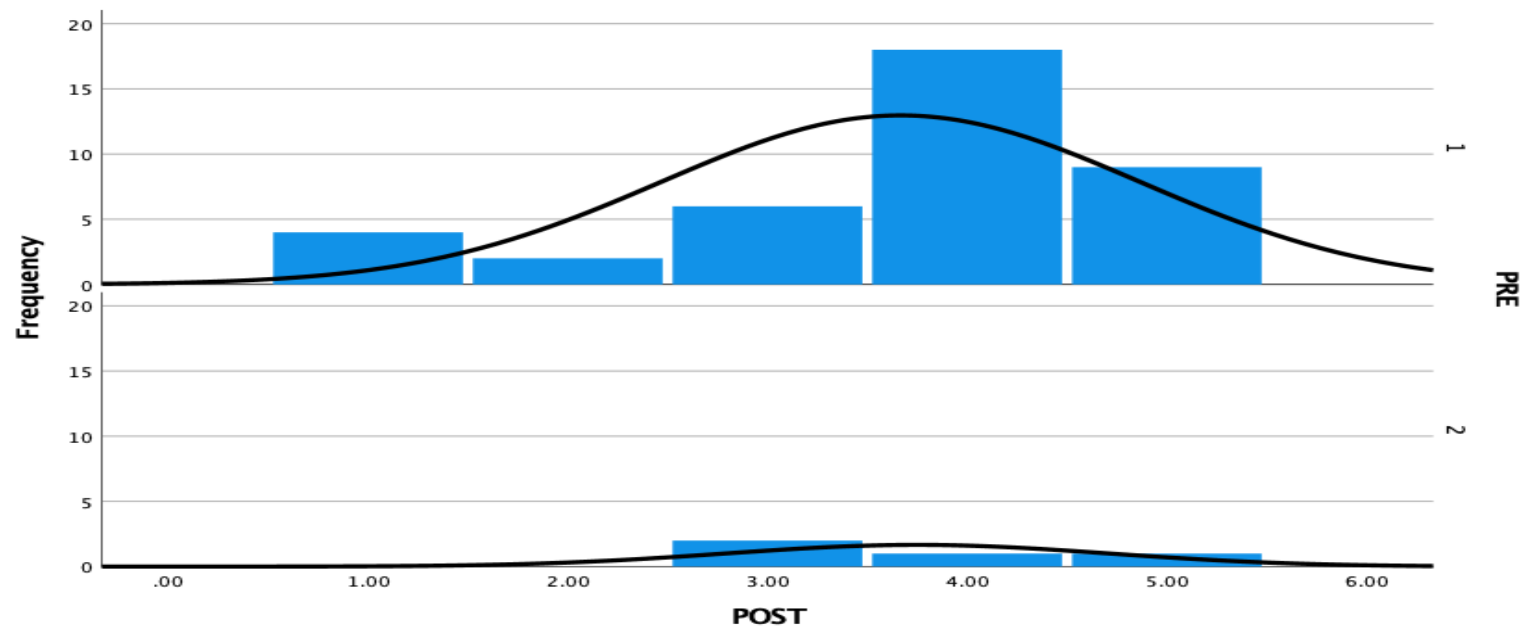

Note. Results of the Mann-Whitney $U$ test disclosed statistically insignificant data pertaining to the intervention's effect on participants' perception of enhanced of patient safety $(p=.856)$. The Z score $(-0.199)$ indicated the data is -0.199 standard deviations to the left of the mean on the bell curve. 


\section{Appendix F \\ Pre-Intervention Survey Results}

\section{Figure 1}

Q1 - What is your assigned role in this procedure?

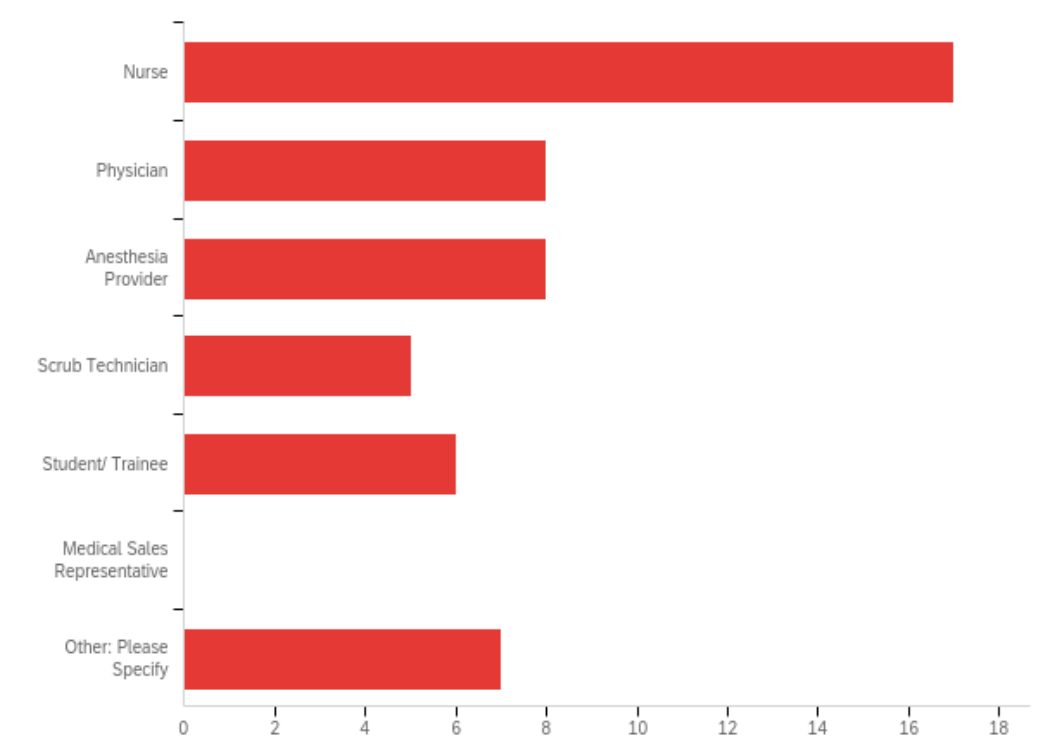

\begin{tabular}{|c|c|c|c|c|c|c|c|}
\hline \# & Field & Minimum & Maximum & Mean & $\begin{array}{r}\text { Std } \\
\text { Deviation }\end{array}$ & Variance & Count \\
\hline 1 & $\begin{array}{r}\text { What is your assigned } \\
\text { role in this procedure? - } \\
\text { Selected Choice }\end{array}$ & 1.00 & 7.00 & 3.06 & 2.06 & 4.25 & 51 \\
\hline
\end{tabular}

\begin{tabular}{|l|r|r|r}
\hline$\#$ & Answer & $\%$ & Count \\
\hline 1 & Nurse & $33.33 \%$ & 17 \\
\hline 2 & Physician & $15.69 \%$ & 8 \\
\hline 3 & Anesthesia Provider & $15.69 \%$ & 8 \\
\hline 4 & Scrub Technician & $9.80 \%$ & 5 \\
\hline 5 & Student/ Trainee & $11.76 \%$ & 6 \\
\hline 6 & Medical Sales Representative & $0.00 \%$ & 0 \\
\hline 7 & Other: Please Specify & $13.73 \%$ & 7
\end{tabular}


Total $\quad 100 \%$

51

Q1_7_TEXT - Other: Please Specify

Other: Please Specify - Text

laser operator

$\mathrm{X}$ ray tech

CST II

RA-C

$\mathrm{x}$ ray tech

resident physician

on site stryker

Note. Results from data analysis. 


\section{Figure 2}

Q2 - How frequently do you work in this urology specialty?

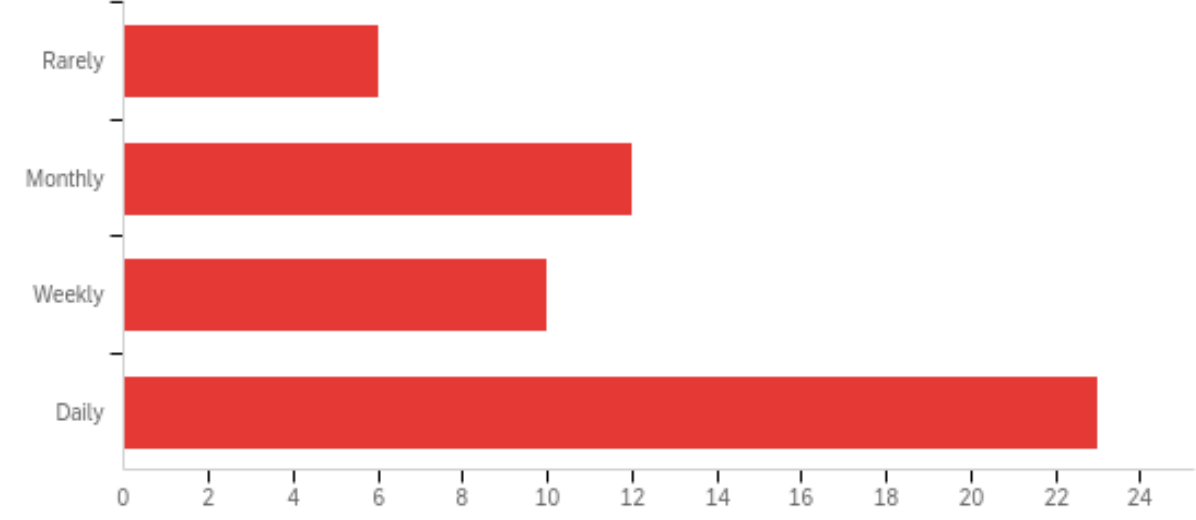

\begin{tabular}{r|r|r|r|r|r|r|r} 
Field & Minimum & Maximum & Mean & $\begin{array}{r}\text { Std } \\
\text { Deviation }\end{array}$ & Variance & Count \\
\hline 1 & $\begin{array}{r}\text { How frequently do you work in } \\
\text { this urology specialty? }\end{array}$ & 1.00 & 4.00 & 2.98 & 1.08 & 1.16 & 51
\end{tabular}

\begin{tabular}{l|r|r|r}
\hline$\#$ & Answer & $\%$ & Count \\
\hline 1 & Rarely & $11.76 \%$ & 6 \\
\hline 2 & Monthly & $23.53 \%$ & 12 \\
\hline 3 & Weekly & $19.61 \%$ & 10 \\
\hline 4 & Daily & $45.10 \%$ & 23 \\
\hline & Total & $100 \%$ & 51 \\
\hline & & &
\end{tabular}

Note. Results from data analysis. 


\section{Figure 3}

Q3 - Has a patient in your care ever had an adverse event related to the inability of providers to identify each other?

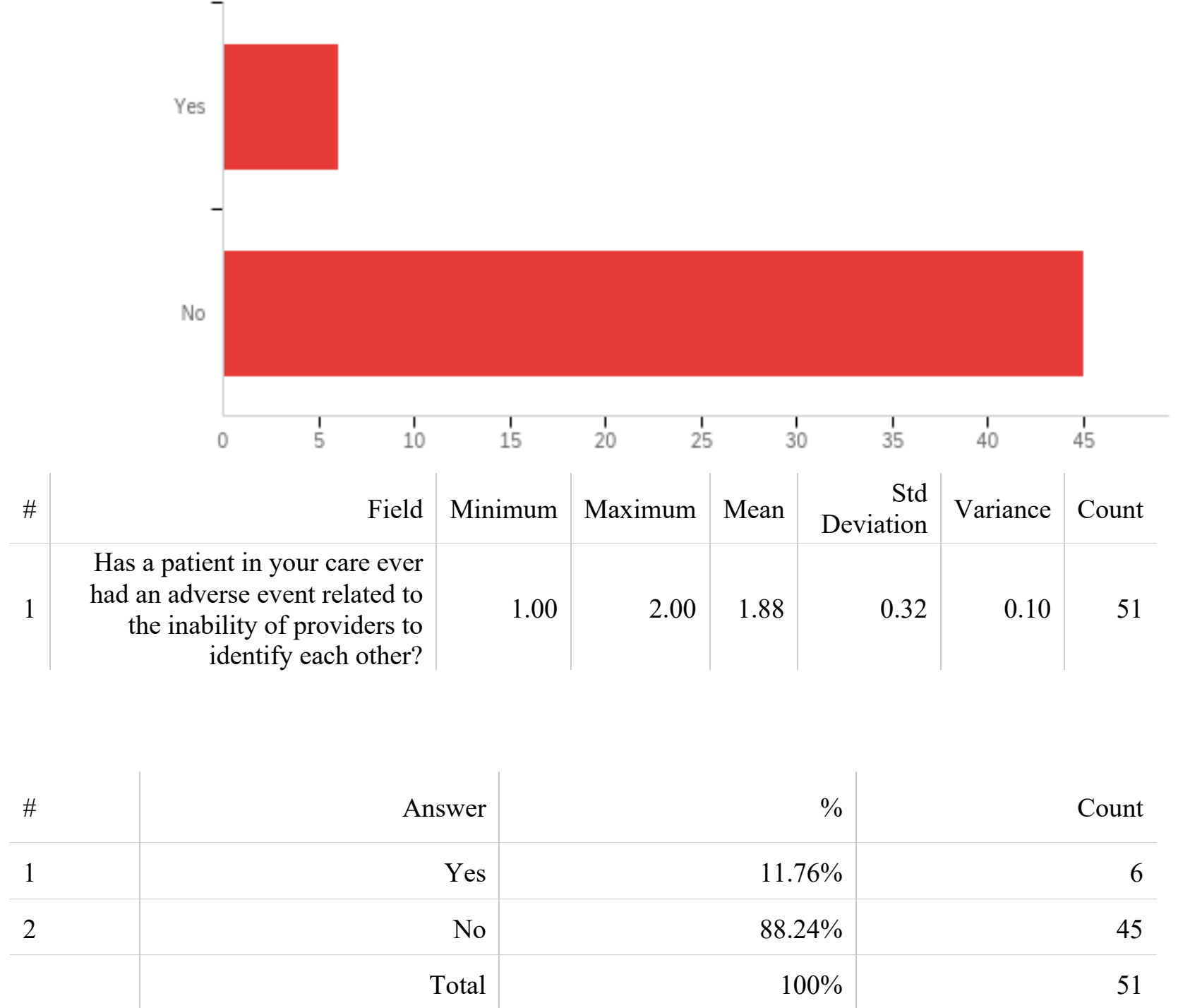

Note. Results from data analysis. 


\section{Figure 4}

\section{Q4 - How difficult is it to identify staff member roles while fully donned in personal protective equipment (PPE)?}

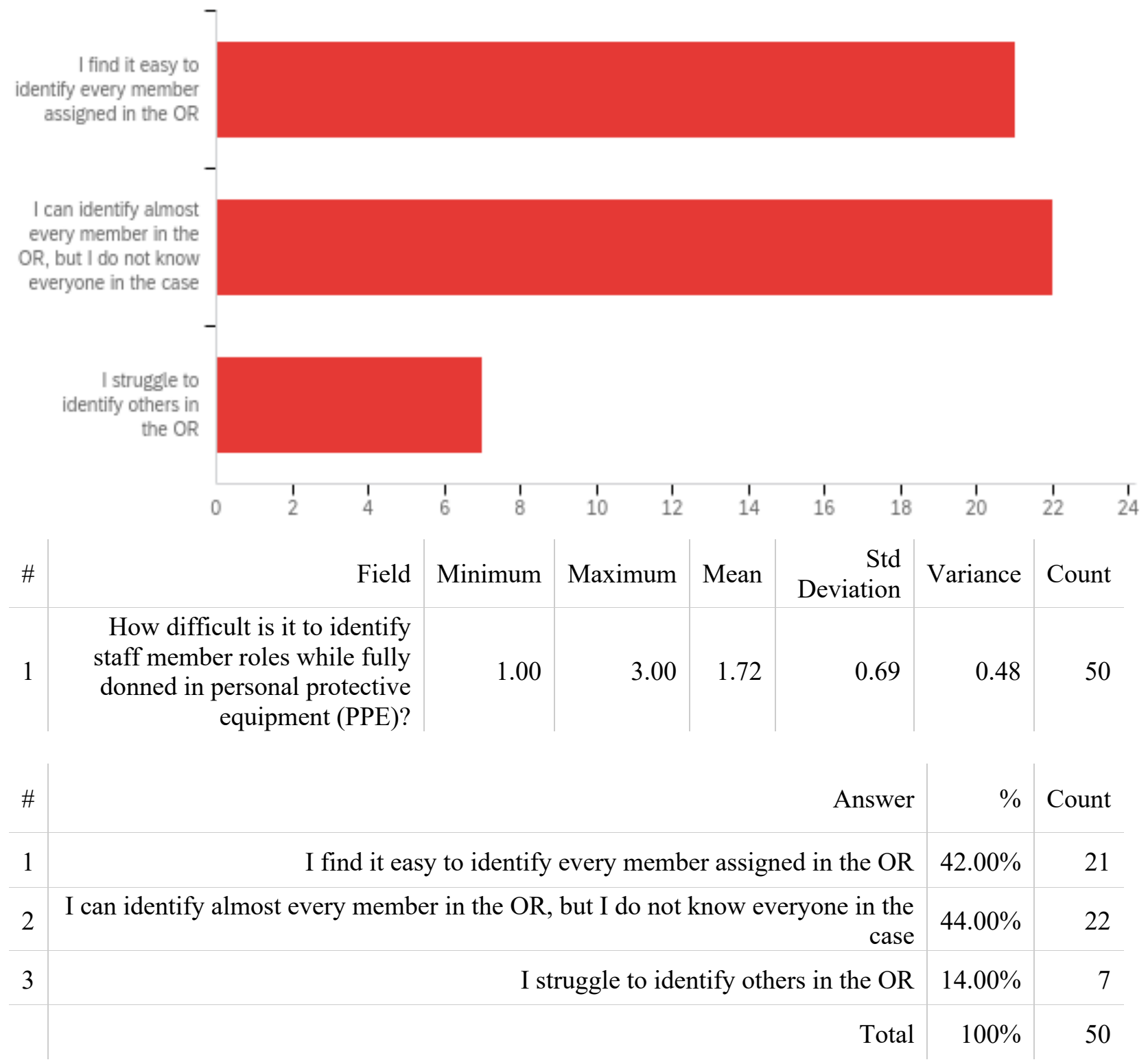

Note. Results from data analysis. 


\section{Figure 5}

Q5 - Do you think that being able to distinguish names and roles would help improve patient's safety?

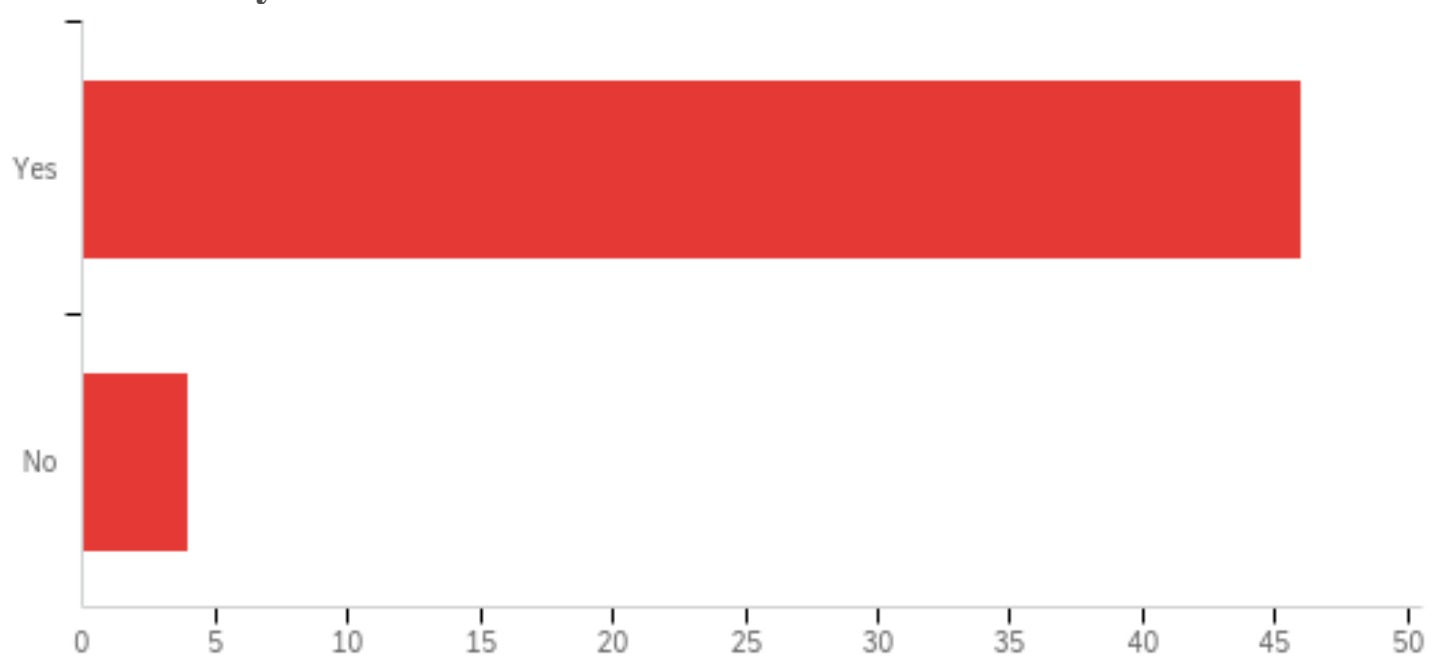

\begin{tabular}{|c|c|c|c|c|c|c|c|c|c|}
\hline \# & Field & \multicolumn{2}{|c|}{ Minimum } & \multirow[t]{2}{*}{ Maximum } & \multirow{2}{*}{$\begin{array}{l}\text { Mean } \\
1.08\end{array}$} & \multicolumn{2}{|c|}{$\begin{array}{r}\text { Std } \\
\text { Deviation }\end{array}$} & \multirow[t]{2}{*}{ Variance } & \multirow{2}{*}{$\begin{array}{r}\text { Count } \\
50\end{array}$} \\
\hline 1 & $\begin{array}{r}\text { Do you think that being able to } \\
\text { distinguish names and roles } \\
\text { would help improve patient's } \\
\text { safety? }\end{array}$ & \multicolumn{2}{|r|}{1.00} & & & \multicolumn{2}{|r|}{0.27} & & \\
\hline \# & \multicolumn{3}{|c|}{ Answer } & \multicolumn{4}{|c|}{$\%$} & \multicolumn{2}{|r|}{ Count } \\
\hline 1 & \multicolumn{3}{|c|}{ Yes } & \multicolumn{4}{|c|}{$92.00 \%$} & \multicolumn{2}{|r|}{46} \\
\hline 2 & \multicolumn{3}{|c|}{ No } & \multicolumn{4}{|c|}{$8.00 \%$} & \multicolumn{2}{|r|}{4} \\
\hline & \multicolumn{3}{|c|}{ Total } & \multicolumn{4}{|c|}{$100 \%$} & \multicolumn{2}{|r|}{50} \\
\hline
\end{tabular}

Note. Results from data analysis. 


\section{Figure 6}

\section{Q6 - What is your most common practice to identify others on the OR team?}

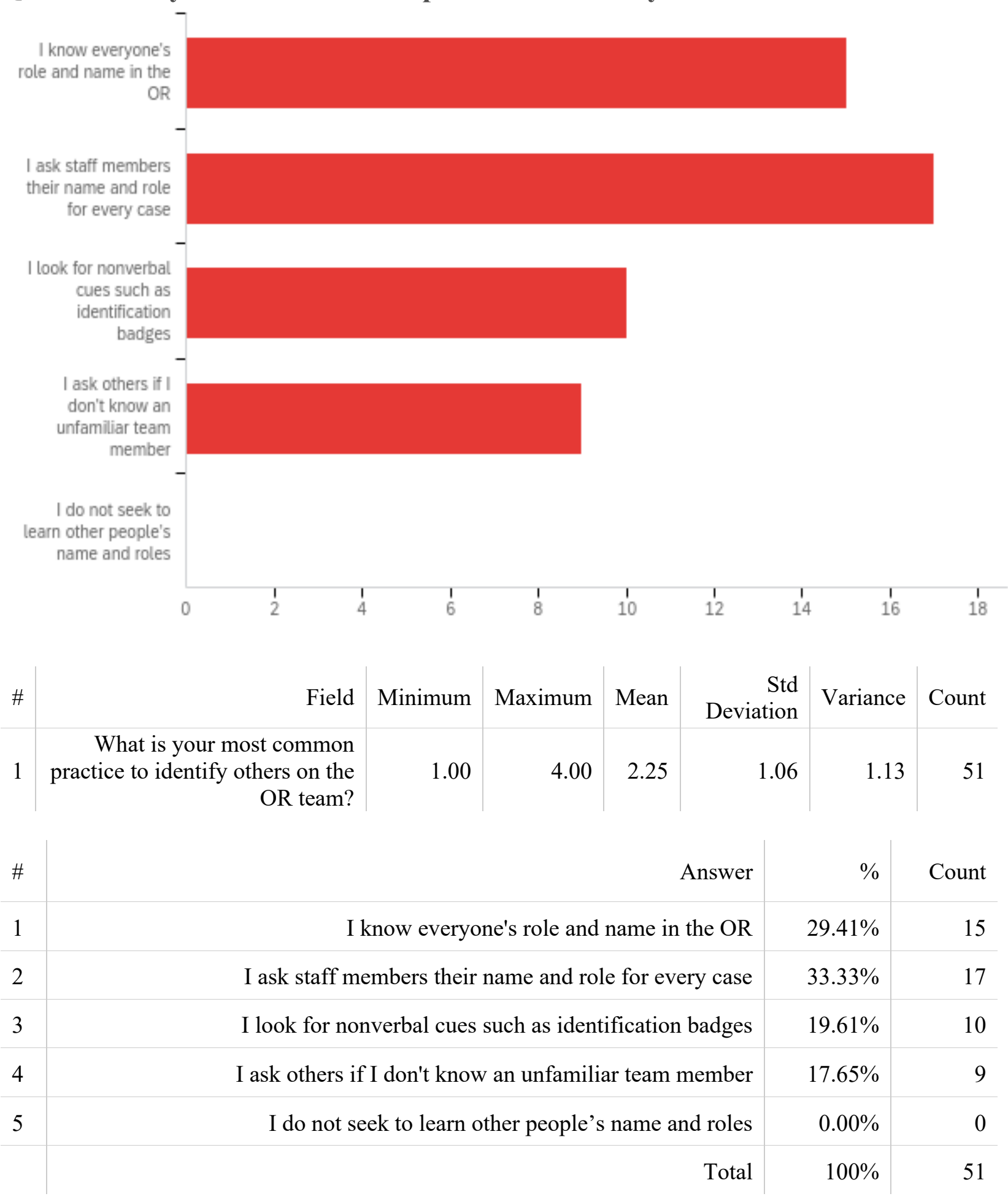

Note. Results from data analysis. 


\section{Figure 7}

\section{Q7 - How often do you introduce yourself to other members of the OR team?}
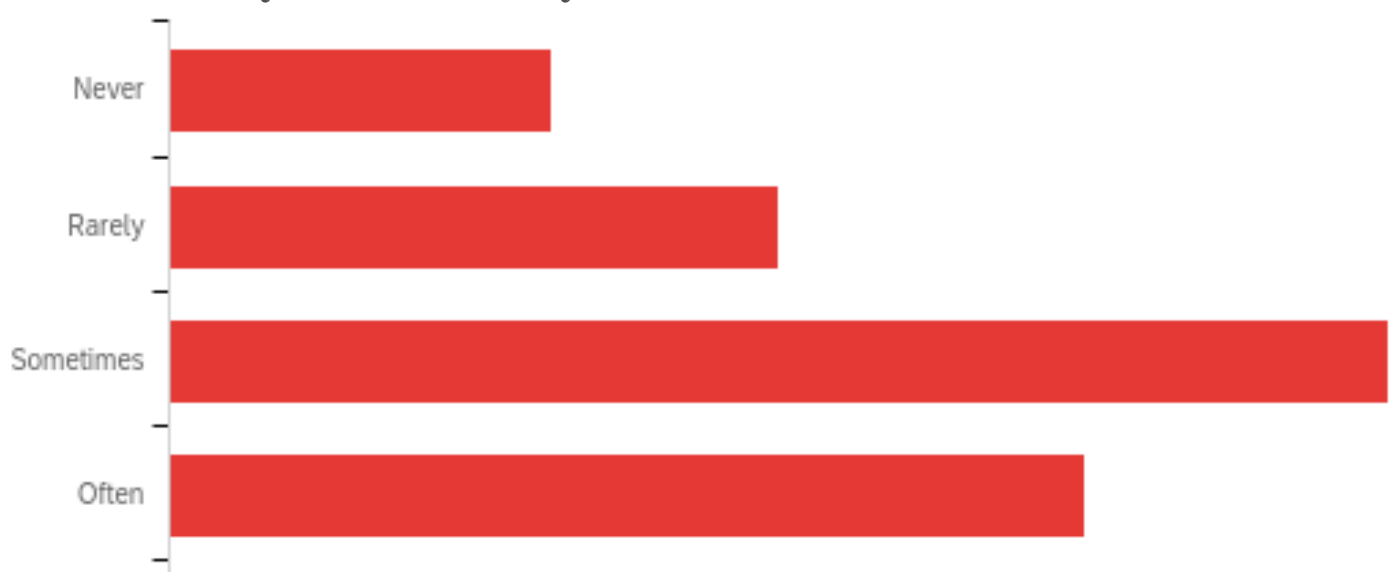

Always
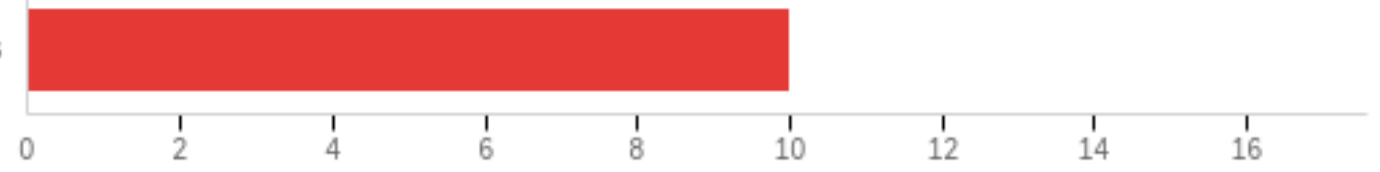

\begin{tabular}{|c|c|c|c|c|c|c|c|}
\hline$\#$ & Field & Minimum & Maximum & Mean & $\begin{array}{r}\text { Std } \\
\text { Deviation }\end{array}$ & Variance & Count \\
\hline & $\begin{array}{r}\text { How often do you introduce } \\
\text { yourself to other members of the } \\
\text { OR team? }\end{array}$ & 1.00 & 5.00 & 3.27 & 1.22 & 1.49 & 51 \\
\hline
\end{tabular}

\begin{tabular}{l|r|r|r}
\hline$\#$ & Answer & $\%$ & Count \\
\hline 1 & Never & $9.80 \%$ & 5 \\
\hline 2 & Rarely & $15.69 \%$ & 8 \\
\hline 3 & Sometimes & $31.37 \%$ & 16 \\
\hline 4 & Often & $23.53 \%$ & 12 \\
\hline 5 & Always & $19.61 \%$ & 10 \\
\hline & Total & $100 \%$ & 51
\end{tabular}

Note. Results from data analysis. 
Figure 8

Q8 - Please indicate your level of agreement with the following statement: Knowing staff members names and role in the OR improves patient's safety.

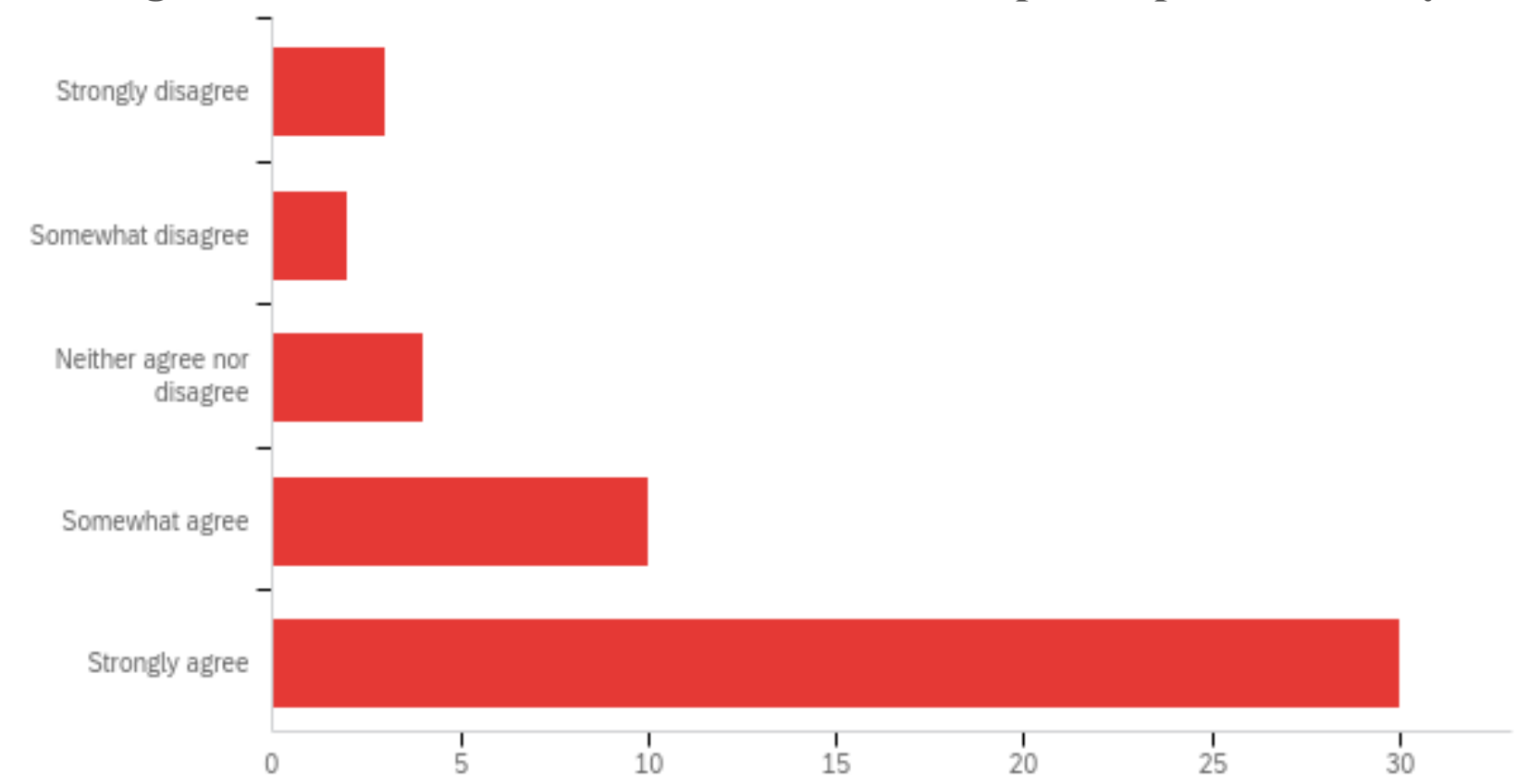

\begin{tabular}{|c|c|c|c|c|c|c|c|}
\hline \# & Field & Minimum & Maximum & Mean & $\begin{array}{r}\text { Std } \\
\text { Deviation }\end{array}$ & Variance & Count \\
\hline 1 & $\begin{array}{l}\text { Please indicate your level of } \\
\text { agreement with the following } \\
\text { statement: Knowing staff } \\
\text { members names and role in the } \\
\text { OR improves patient's safety. }\end{array}$ & 1.00 & 5.00 & 4.27 & 1.16 & 1.34 & 49 \\
\hline \# & \multicolumn{3}{|r|}{ Answer } & & $\%$ & & Count \\
\hline 1 & \multicolumn{3}{|c|}{ Strongly disagree } & & $6.12 \%$ & & 3 \\
\hline 2 & \multicolumn{3}{|c|}{ Somewhat disagree } & & $4.08 \%$ & & 2 \\
\hline 3 & \multicolumn{3}{|c|}{ Neither agree nor disagree } & & $8.16 \%$ & & 4 \\
\hline 4 & \multicolumn{3}{|c|}{ Somewhat agree } & & $20.41 \%$ & & 10 \\
\hline 5 & \multicolumn{3}{|c|}{ Strongly agree } & & $61.22 \%$ & & 30 \\
\hline & \multicolumn{3}{|c|}{ Total } & & $100 \%$ & & 49 \\
\hline
\end{tabular}

Note. Results from data analysis. 


\section{Figure 9}

Q9 - Please indicate your level of agreement with the following statement: Knowing staff members names and roles can improve team performance among unfamiliar, de-identified team members dressed in OR PPE.

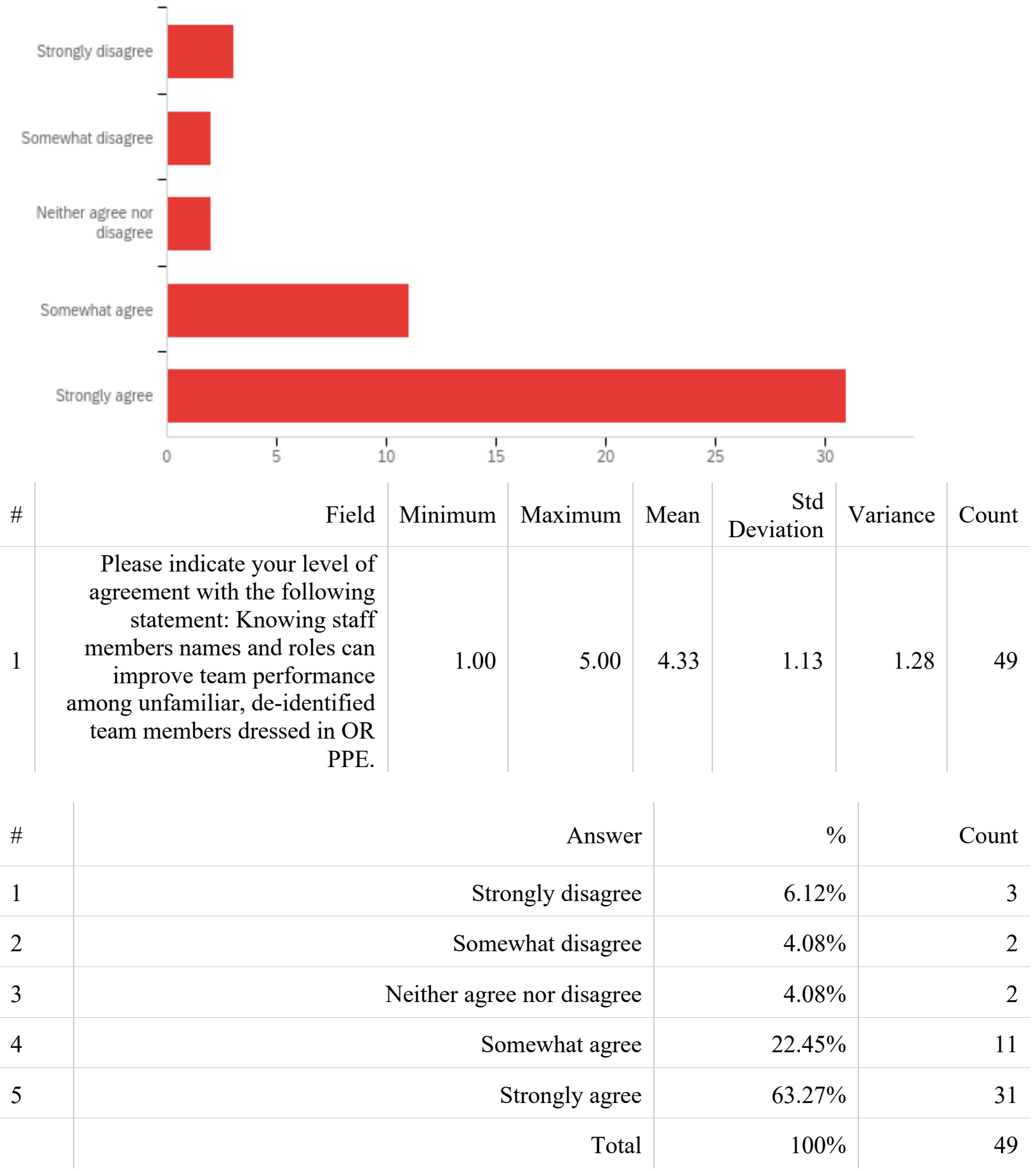

Note. Results from data analysis. 


\section{Appendix G}

\section{Post- Intervention Results}

\section{Figure 1}

Q1 - What is your assigned role in this procedure?

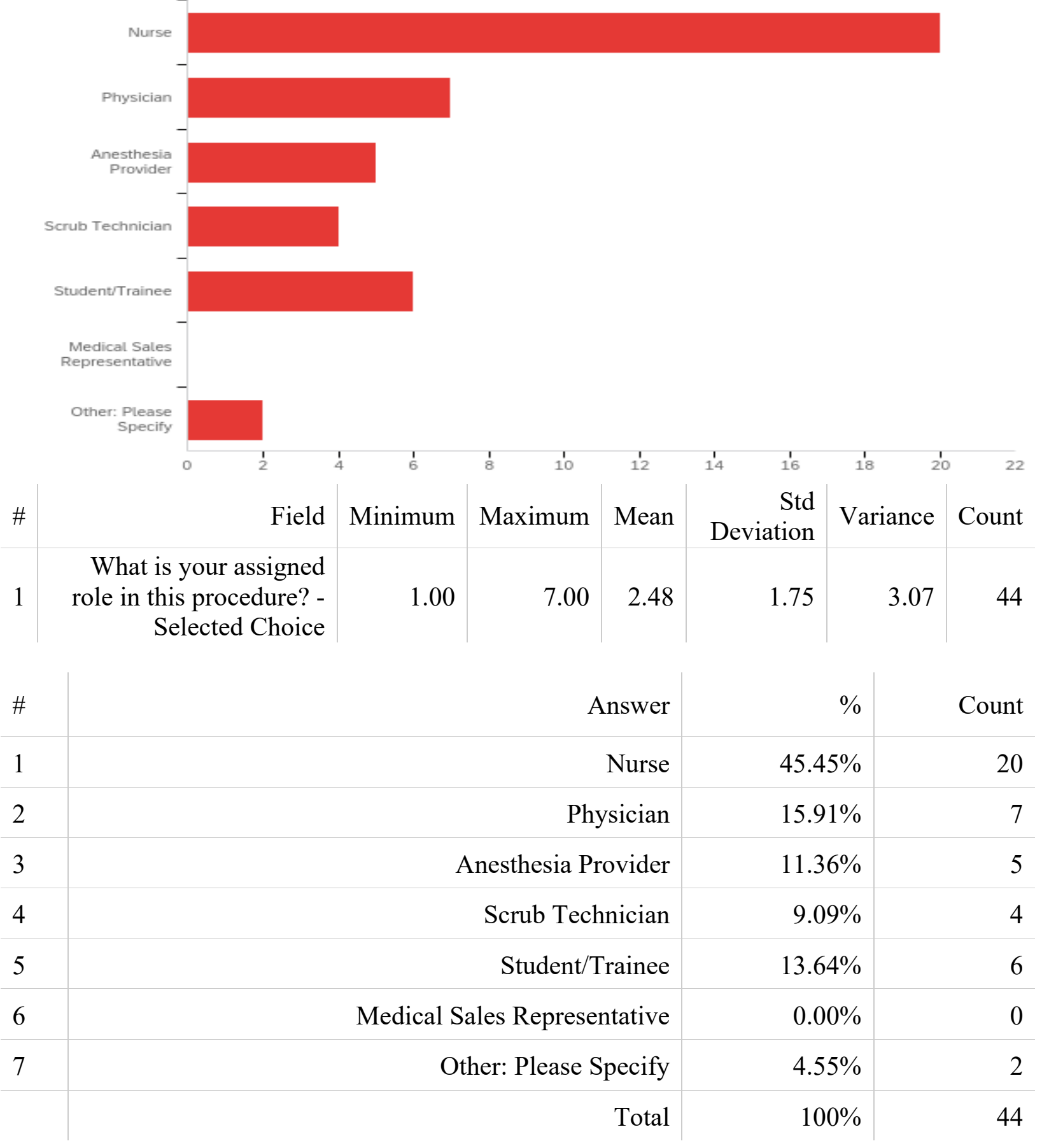


Other: Please Specify - Text

CST III

$\mathrm{X}$ ray Tech

Note. Results from data analysis. 


\section{Figure 2}

Q2 - How frequently do you work with the staff in today's procedure?

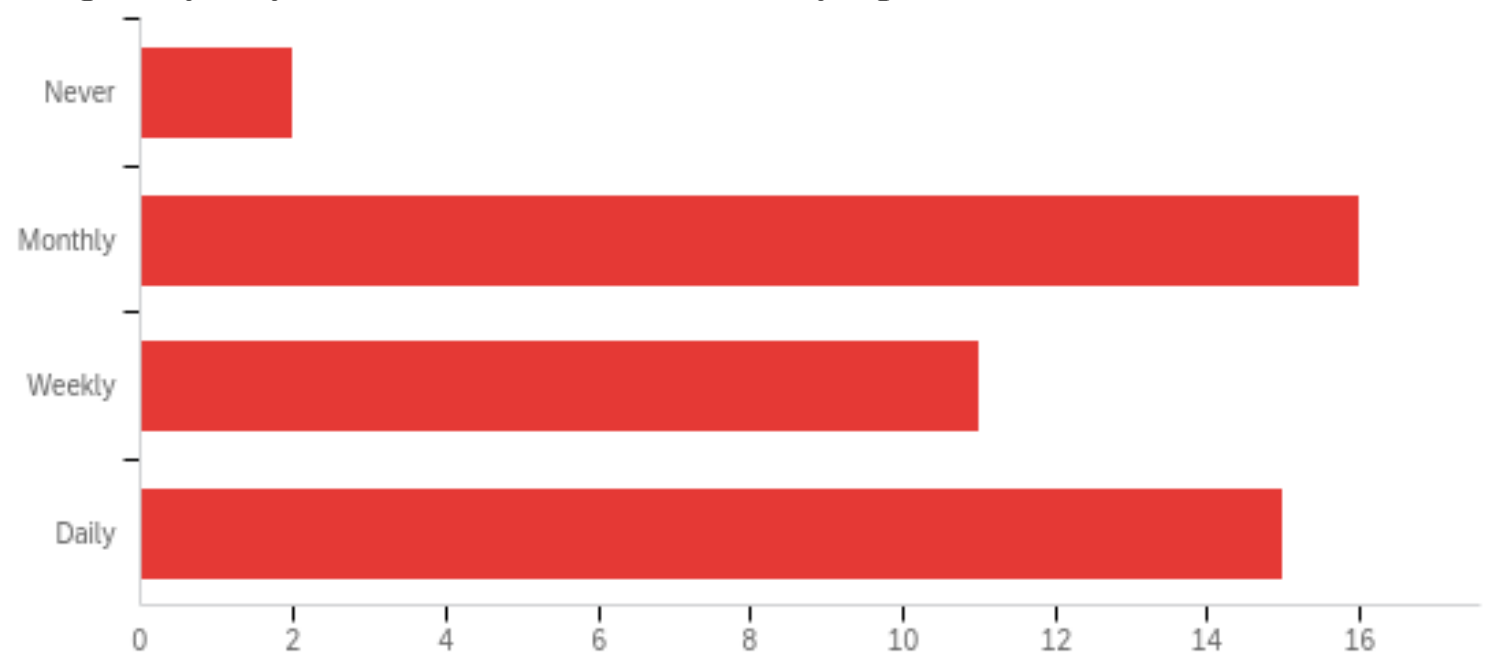

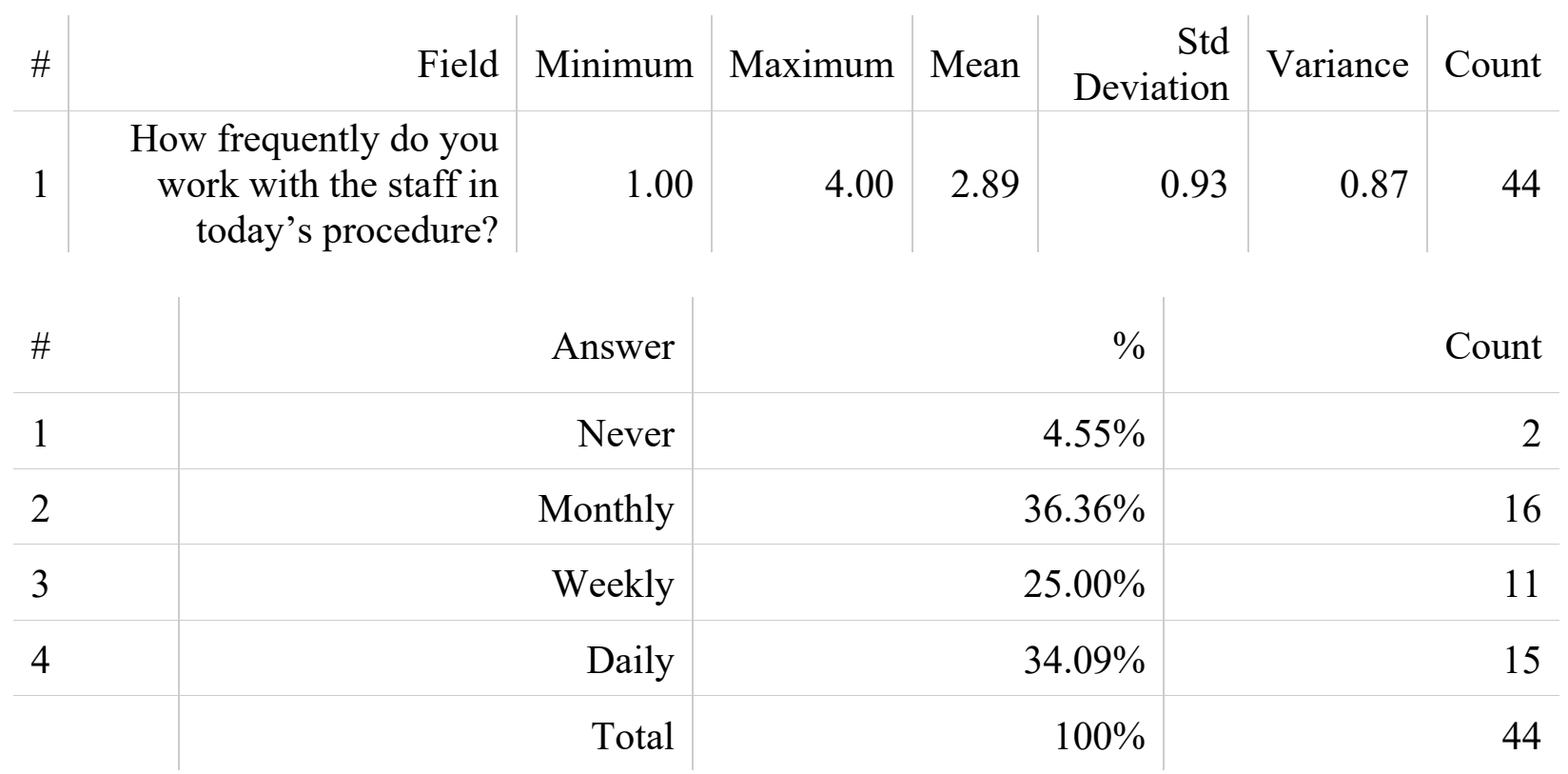

Note. Results from data analysis. 


\section{Figure 3}

Q3 - How many staff members did you know in the procedure?

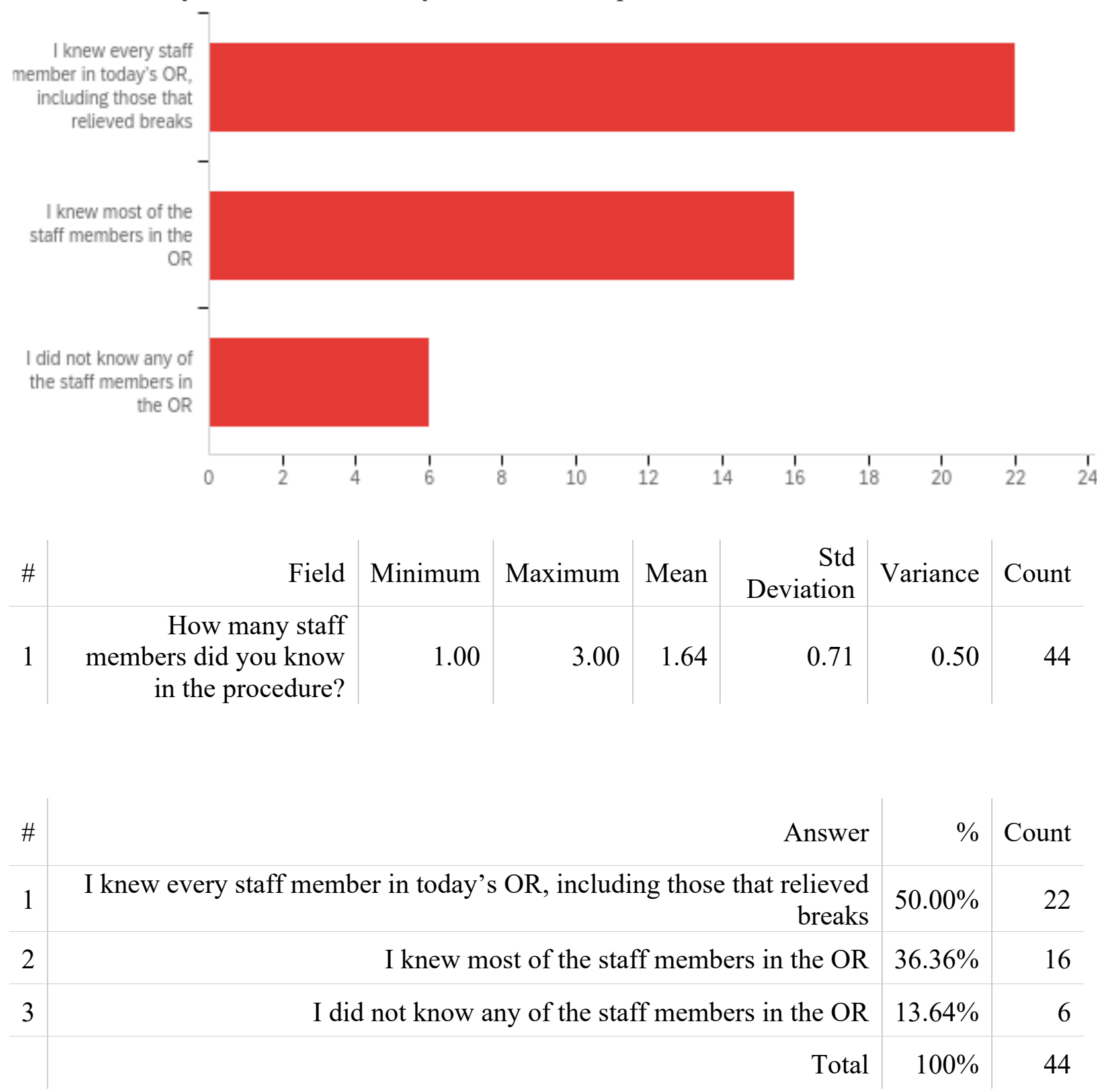

Note. Results from data analysis. 


\section{Figure 4}

Q4 - Identify the team member(s) that you did not know (select multiple if applicable)

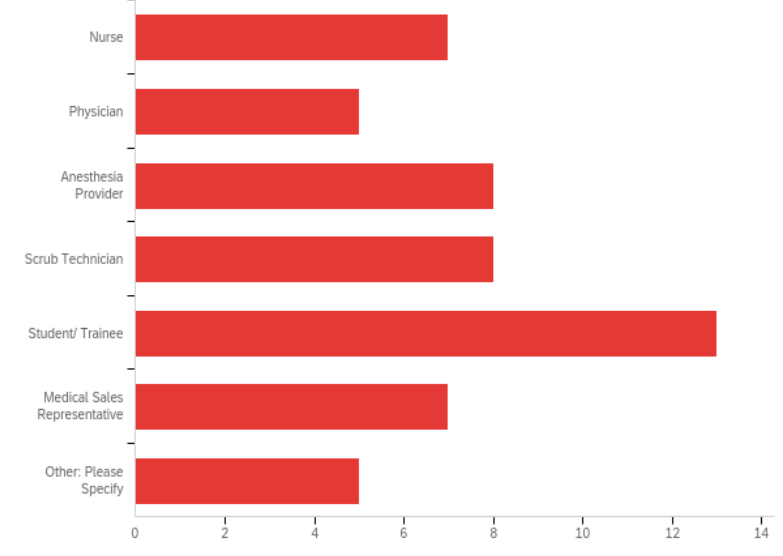

\begin{tabular}{l|r|r|r}
\hline$\#$ & Answer & $\%$ & Count \\
\hline 1 & Nurse & $13.21 \%$ & 7 \\
\hline 2 & Physician & $9.43 \%$ & 5 \\
\hline 3 & Anesthesia Provider & $15.09 \%$ & 8 \\
\hline 4 & Scrub Technician & $15.09 \%$ & 8 \\
\hline 5 & Student/ Trainee & $24.53 \%$ & 13 \\
\hline 6 & Medical Sales Representative & $13.21 \%$ & 7 \\
\hline 7 & Other: Please Specify & $9.43 \%$ & 5 \\
\hline & Total & $100 \%$ & 53
\end{tabular}

Q4_7_TEXT - Other: Please Specify

Other: Please Specify - Text

Resident, X ray tech

$\mathrm{X}$ ray tech

X ray tech

$\mathrm{X}$ ray tech

Med student/ D.O. resident

Note. Results from data analysis. 


\section{Figure 5}

Q5 - To what degree do you feel that a nonverbal identification system displaying name and role on scrub caps enhances communication among OR team members?

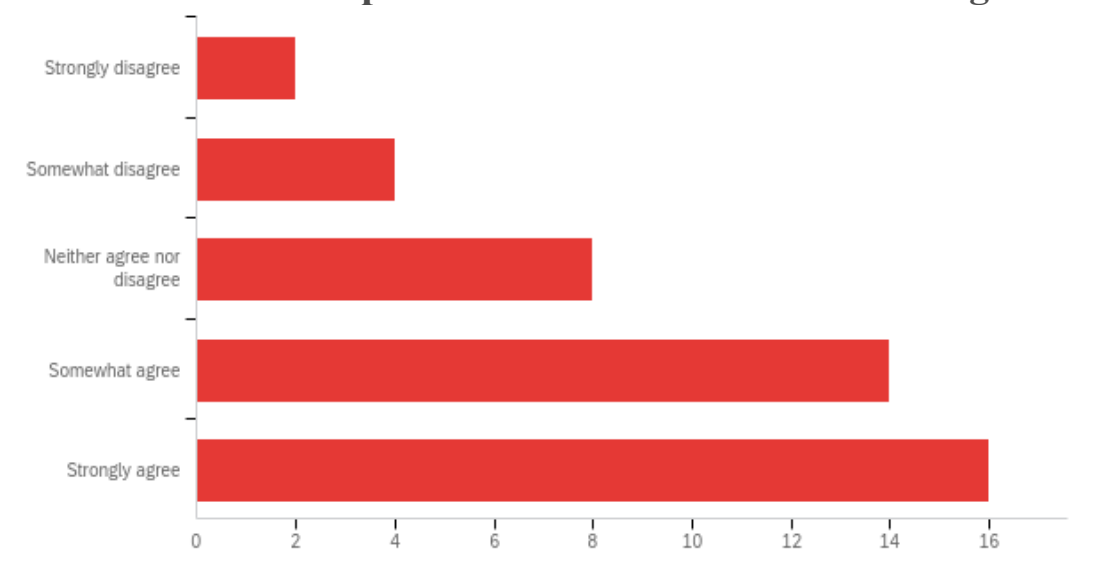

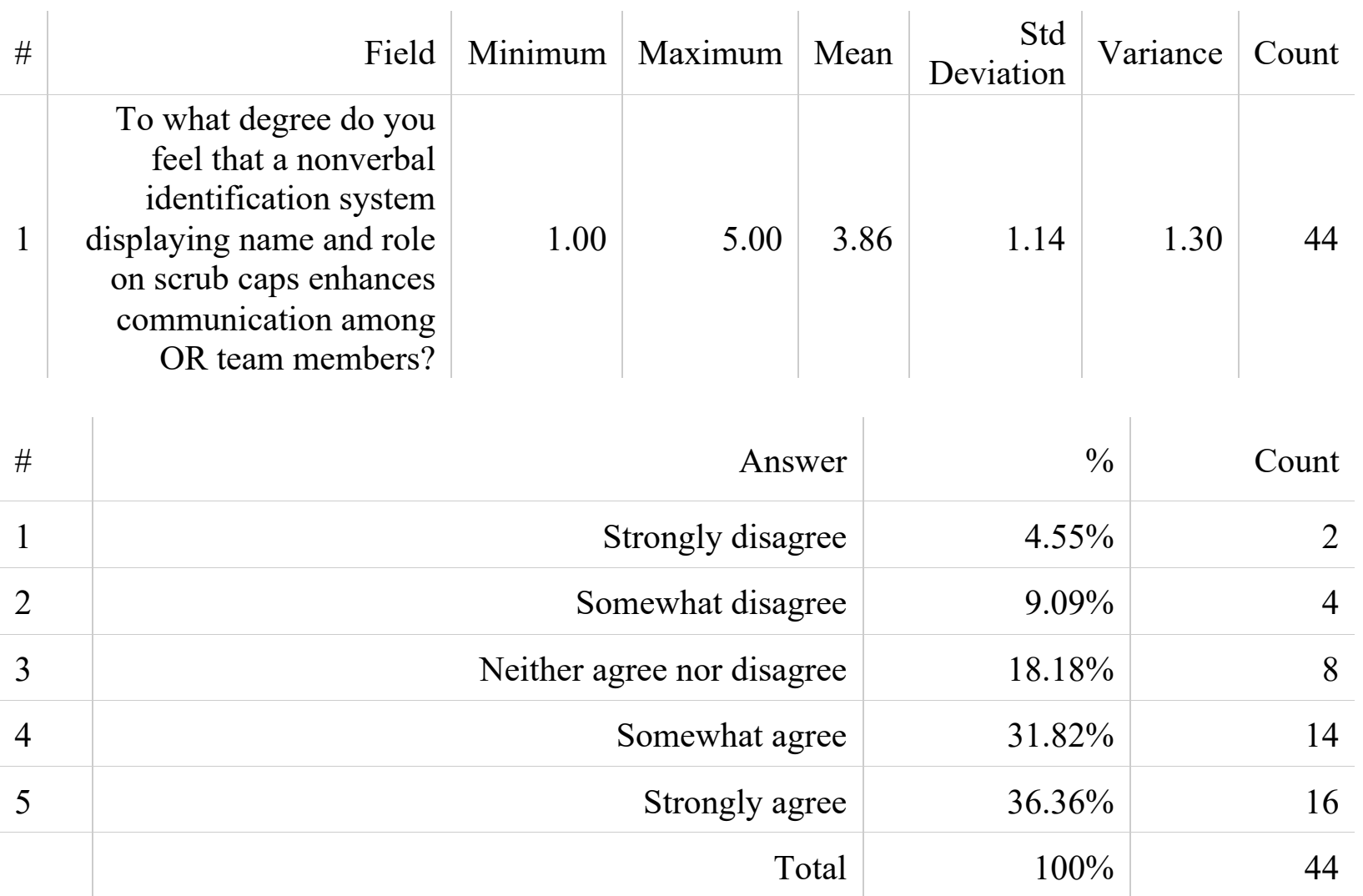

Note. This Likert scaled question was used to rank data to meet the second aim's objective. This aim was achieved as more than half of participants reported that the intervention enhanced the perception of patient safety. 


\section{Figure 6}

Q6 - To what degree do you feel that a nonverbal identification system displaying name and role on scrub caps enhances patient safety in the OR?

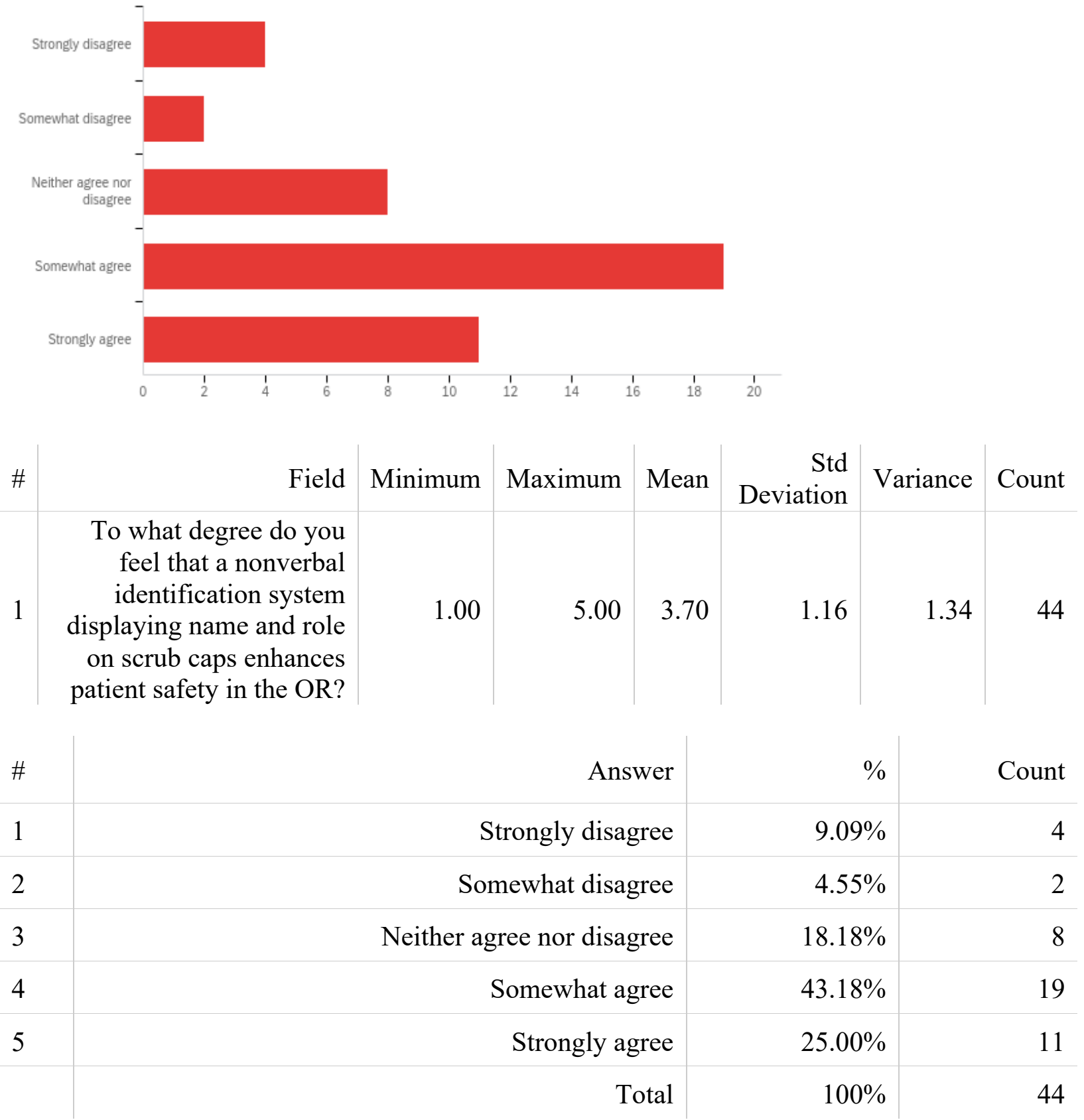

Note. This question was compared in the Mann-Whitney U test to determine statistical

significance of the intervention's effect on the perception of improved patient safety. 


\section{Figure 7}

Q7 - How willing would you be to adopt scrub cap identification into your practice if there was a benefit to patient care?

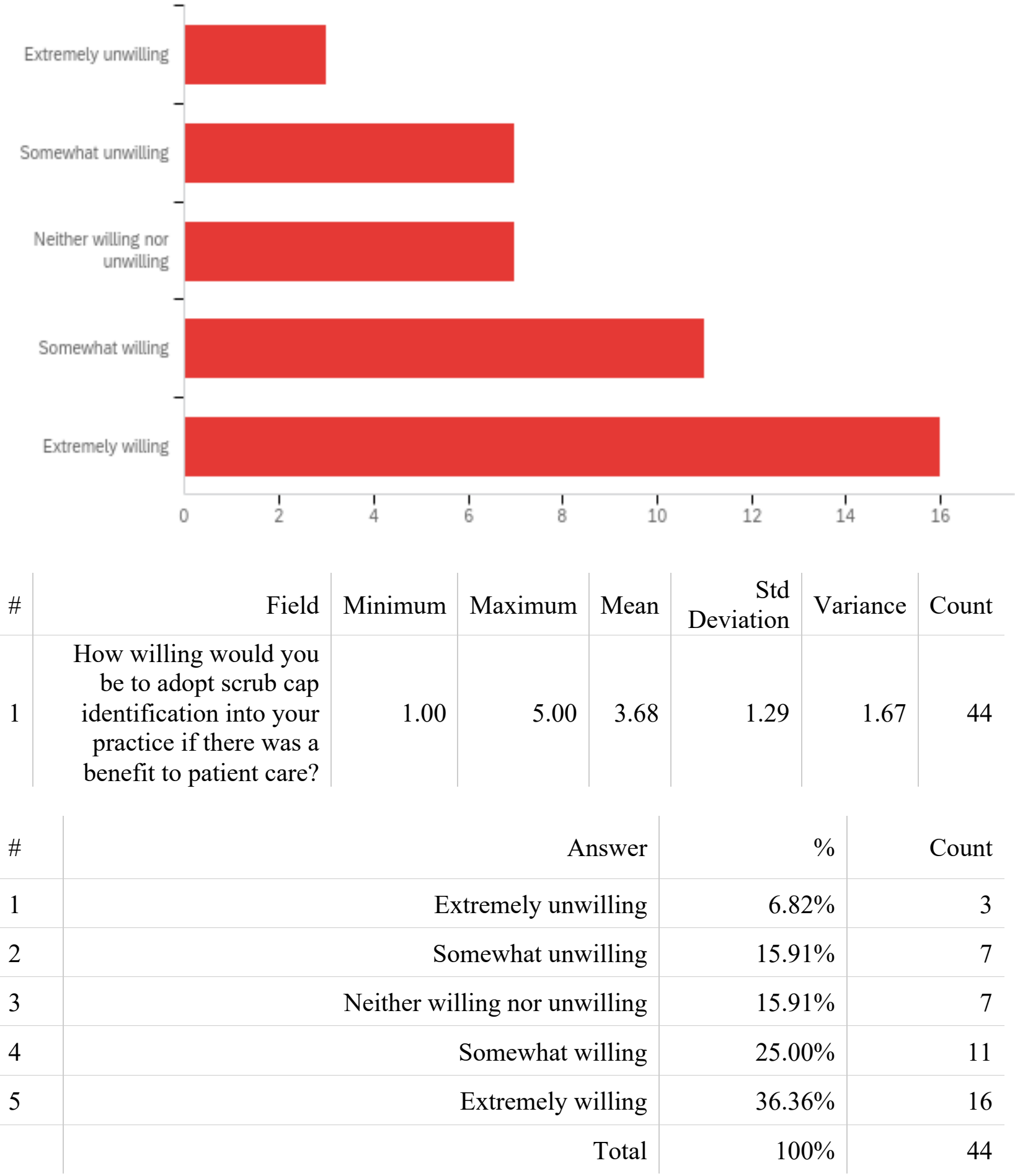

Note. This question measured the sustainability of the project. More than half of participants reported a "willingness" to adopt the intervention into practice. 


\section{Figure 8}

Q8 - What ways can this intervention be improved in the future?

What ways can this intervention be improved in the future?

In 209 the study isn't going to have the same results as it would in an OR with more complex cases/ more staff

study use in a more complex/ procedure Or with more variety of staff more numbers of staff

If we had embroidered scrub caps, otherwise, no

aside from this intervention, $\mathrm{i}$ believe that the other nest thing is to follow by heart the initiation of the flow o the surgeon of time out from beginning from introduction of surgical team members and other people and role in the room. I have been working in this ore than 10 a week for years in rm. 209 so i basically know the surgical team and others who come

encourage this to be performed by the time-out

make a spot for OR rooms Dates and floor!

have it stitched in caps so it appears more professional

team members can already have hats that include their name + title

self identification instead of hat ID ( I.E team members share their name and role during time out

we had color coded hat in the past- problem was enforcing employees to wear correct hat

\begin{tabular}{r|r|r|r}
$\#$ & Answer & $\%$ & Count \\
\hline 1 & Unknown & $100.00 \%$ & 5 \\
\hline & Total & $100 \%$ & 5
\end{tabular}

Note: This question was used to determine future improvements from this QI pilot project. 